\title{
Pressure Effect of the Mechanical, Electronics and Thermodynamic Properties of Mg-B Compounds: A First-Principles Investigation
}

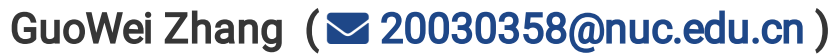

North University of China

\section{Chao Xu}

North University of China

MingJie Wang

North University of China

Hong Xu

North University of China

Ying Dong

North University of China

\section{FengEr Sun}

North University of China

Xiaoyan Ren

North University of China

Yuhong Zhao

North University of China

\section{Research Article}

Keywords: First principle, Mg-B compounds, Anisotropy, Mechanical and electronic properties,

Thermodynamicproperties

Posted Date: January 21st, 2021

DOl: https://doi.org/10.21203/rs.3.rs-149224/v1

License: (c) (i) This work is licensed under a Creative Commons Attribution 4.0 International License.

Read Full License

Version of Record: A version of this preprint was published at Scientific Reports on March 17th, 2021. See the published version at https://doi.org/10.1038/s41598-021-85654-z. 


\title{
Pressure effect of the mechanical, electronics and thermodynamic properties of Mg-B compounds: A first-principles investigation
}

\author{
GuoWei Zhang *, Chao Xu, MingJie Wang, Ying Dong, FengEr Sun, XiaoYan Ren, Hong Xu and \\ YuHong Zhao
}

School of Materials Science and Engineering, North University of China, Shanxi 030051, China

Correspondence: zhangguowei@nuc.edu.cn; Tel: 13703583832

\begin{abstract}
First principle calculations were performed to investigate the structural, mechanical, electronic properties, and thermodynamic properties of three binary $\mathrm{Mg}-\mathrm{B}$ compounds under pressure, by using the first principle method. The results implied that the structural parameters and the mechanical properties of the Mg-B compounds without pressure are well matched with the obtainable theoretically simulated values and experimental data. The obtained pressure-volume and energy-volume revealed that the three $\mathrm{Mg}$ - $\mathrm{B}$ compounds were mechanically stable, and the volume variation decreases with an increase in the boron content. The shear and volume deformation resistance indicated that the elastic constant $C_{i j}$ and bulk modulus $\mathrm{B}$ increased when the pressure increased up to $40 \mathrm{GPa}$, and that $\mathrm{MgB}_{7}$ had the strongest capacity to resist shear and volume deformation at zero pressure, which indicated the highest hardness. Meanwhile, $\mathrm{MgB}_{4}$ exhibited a ductility transformation behaviour at $30 \mathrm{GPa}$, and $\mathrm{MgB}_{2}$ and $\mathrm{MgB}_{7}$ displayed a brittle nature under all the considered pressure conditions. The anisotropy of the three $\mathrm{Mg}-\mathrm{B}$ compounds under pressure were arranged as follows: $\mathrm{MgB}_{4}>\mathrm{MgB}_{2}>\mathrm{MgB}_{7}$. Moreover, the total density of states (TDOS) varied slightly and decreased with an increase in the pressure. The Debye temperature $\Theta_{\mathrm{D}}$ of the Mg-B compounds gradually increased with an increase in the pressure and the boron content. The temperature and pressure dependence of the heat capacity and the linear thermal expansion coefficient $\alpha$ were both obtained on the basis of Debye model under increased pressure from 0GPa to $40 \mathrm{GPa}$ and increased temperatures. This paper brings a convenient understanding of the magnesium-boron alloys.
\end{abstract}

Keywords: First principle; Mg-B compounds; Anisotropy; Mechanical and electronic properties; Thermodynamic properties

\section{Introduction}

Magnesium boride alloys $\left(\mathrm{MgB}_{2}, \mathrm{MgB}_{4}\right.$, and $\left.\mathrm{MgB}_{7}\right)$ as desirable compounds play an important role in many fields due to their remarkable conductivity, excellent ductility, and high hardness [1-3]. Usually, boron-rich magnesium alloys have excellent material characteristics such as mechanical properties and stability [4-5]. Moreover, $\mathrm{MgB}_{2}$ has been widely introduced into magnesium alloys for reinforcement and grain refinement [6-7], because of the chemical substitution and the crystal growth of substituted $\mathrm{MgB}_{2}$ [8-11]. Therefore, increasing attention has been paid to the investigation of magnesium boride alloys in many academic fields.

Superconductors of magnesium diboride were reported first by Akimitsu [12] in 2001. Since then, magnesium boride systems have been extensively studied through theoretical simulations and experimental analyses [13-15]. The intermediate phases of $\mathrm{Mg}-\mathrm{B}$ alloys, which include $\mathrm{MgB}_{2}, \mathrm{MgB}_{4}$, and $\mathrm{MgB}_{7}$, were found through the continued investigation of the $\mathrm{Mg}-\mathrm{B}$ binary phase diagram using the CALPHAD method based on experimental data [16-17]. Furthermore, Brutti et al. [18] studied the vaporisation behaviour of $\mathrm{MgB}_{2}$ and $\mathrm{MgB}_{4}$ by the Knudsen effusion-mass spectrometry 
technique. Wenzel et al. [19] predicted the crystal system and the lattice parameters of Mg-B compounds by using the electron probe micro analysis (EPMA) and X-ray diffraction (XRD) analytical approaches. Moreover, the lattice parameters of Mg-B compounds were calculated using the first principle based on the density functional theory (DFT) by Alapati et al. [20]. The elastic constants, mechanical properties, bond structure, and electronic properties of $\mathrm{MgB}_{7}$ at $0 \mathrm{GPa}$ were investigated by Ozisik [21]. Furthermore, the heat capacity and the thermal expansion of $\mathrm{MgB}_{2}$ at 0 GPa was predicted via DFT calculations by Saengdeejing [22]. The thermodynamic properties of $\mathrm{Mg}-\mathrm{B}$ compounds and $\mathrm{Al}-\mathrm{Mg}-\mathrm{B}$ films were also investigated by using ab initio calculations and CALPHAD methods [23-24]. Nevertheless, the structural stability of Mg-B compounds under thermodynamic conditions have not been reported as yet. Moreover, the crystal structure, electronic properties, thermodynamic properties, and mechanical properties of $\mathrm{Mg}-\mathrm{B}$ compounds at different pressure and temperature have not been studied.

Assuredly, the above mentioned experimental studies have evidenced that the properties of Mg-B compounds can be calculated using DFT for establishing the trends of stability through the cohesive energies and the trends of charge transfers onto boron. Therefore, in the current article, the structural, mechanism, electronic, and anisotropic properties of $\mathrm{MgB}_{2}, \mathrm{MgB}_{4}$, and $\mathrm{MgB}_{7}$ under pressure from 0 to $40 \mathrm{GPa}$ were investigated by using the VASP (Vienna Ab-initio Simulation Package) codes. The linear thermal expansion coefficient, Debye temperature, heat capacity, and other thermodynamic properties were entirely studied theoretically for determining the pressure and temperature dependence of $\mathrm{Mg}-\mathrm{B}$ compounds.

\section{Computational methodology}

In this study, all the calculated results were obtained using the first-principle method through the Vienna ab initio simulation package (VASP) [25] codes. PBE (Perdew-Burke-Ernzerhof) [27] in GGA (generalized gradient approximation) was performed to expound the exchange-correction function [26] and calculate the self-consistent electronic density. All the calculations in the current study considered $\mathrm{Mg} 3 \mathrm{p}^{6} 3 \mathrm{~s}^{2}$ and B $2 \mathrm{~s}^{2} 2 \mathrm{p}^{1}$ as the valence electrons. To obtain an accurate calculated results, the cut-off energy $E_{\text {cut }}$ was set to $500 \mathrm{eV}$. Moreover, the Brillouin-zone sampling mesh for the Monkhorst-Pack [28] k-point for $\mathrm{MgB}_{2}, \mathrm{MgB}_{4}$, and $\mathrm{MgB}_{7}$ was set to $19 \times 19 \times 14,9 \times 11 \times 7$, and 8 $\times 8 \times 8$, respectively, due to the k-mesh was forced to be centred on the gamma point. Besides, the $\sigma$ value of the first-order Methfessel-Paxton smearing was set to $0.2 \mathrm{eV}$, the convergence threshold of the self-consistent field was set to $1.0 \times 10^{-5} \mathrm{eV} /$ atom. Generally, the band gap calculated by GGA is lower than that of experimental results, but the relative value is still very accurate. Thus, GGA as an effective approximation method is used to calculated the electronic properties and band structure.

\section{Results and discussions}

\subsection{Structural stability}

The optimised crystal texture of Mg-B compounds is shown in Figure 1, and the corresponding calculated crystal parameters of the Mg-B compounds at 0 GPa are tabulated in Table 1 [29-31]. As listed in Table 1, the simulated crystal structure parameters considered in this study matched well with the reported literature data from the experimental and theoretical calculations, which verified the reasonability of the Mg-B compound models. 

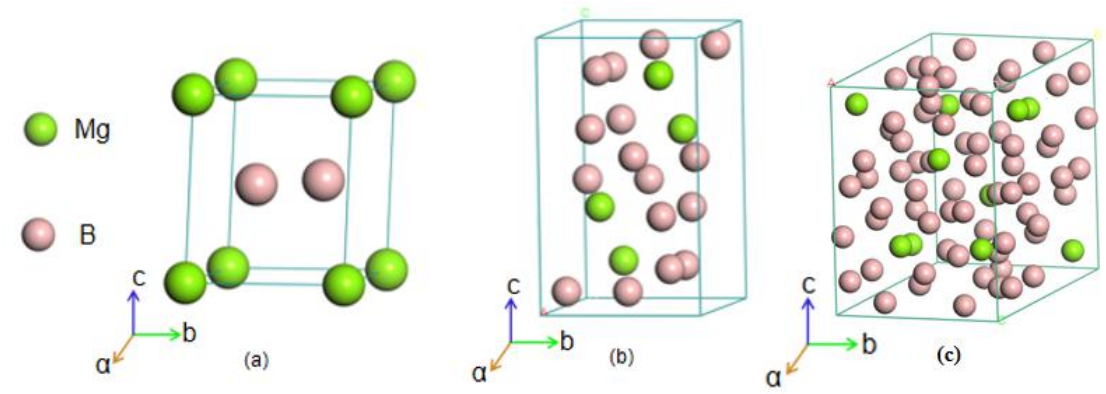

Figure 1. Optimised crystal structures of Mg-B compounds: (a) MgB2; (b) MgB4; (c) MgB7.

Table 1. The simulated structure parameter of Mg-B compounds contained lattice constant $(\AA)$, bulk modulus $B$, and its derivative $\mathrm{B}_{0}{ }^{\prime}$.

\begin{tabular}{|c|c|c|c|c|c|c|c|c|c|}
\hline \multirow[t]{2}{*}{ Phase } & \multirow{2}{*}{$\begin{array}{l}\text { Compositi } \\
\text { on (at } \% \text { B) }\end{array}$} & \multirow{2}{*}{$\begin{array}{c}\text { Magnesium } \\
\text { site }\end{array}$} & \multirow{2}{*}{$\begin{array}{l}\text { Space } \\
\text { group }\end{array}$} & \multicolumn{3}{|c|}{$\begin{array}{l}\text { Unit cell lattice } \\
\text { parameter }(\AA)\end{array}$} & \multirow{2}{*}{$\begin{array}{c}\mathrm{B}_{0}(\mathrm{GPa} \\
\quad)\end{array}$} & \multirow[t]{2}{*}{$\mathrm{B}_{0}^{\prime}$} & \multirow[t]{2}{*}{ reference } \\
\hline & & & & $\mathrm{a}$ & $\mathrm{b}$ & c & & & \\
\hline \multirow[t]{2}{*}{$\mathrm{MgB}_{2}$} & 66.7 & $1 \mathrm{a}(0,0,0)$ & $\begin{array}{c}\mathrm{P} 6 / \mathrm{mm} \\
\mathrm{m}\end{array}$ & 3.07 & 3.07 & 3.53 & 151.7 & 3.54 & $\begin{array}{l}\text { This } \\
\text { work }\end{array}$ \\
\hline & & & & 3.08 & 3.08 & 3.52 & 157.0 & 3.50 & $\operatorname{cal}[29-30]$ \\
\hline \multirow[t]{2}{*}{$\mathrm{MgB}_{4}$} & 80 & $\begin{array}{c}4 \mathrm{c}(0.25,0.546 \\
0.362)\end{array}$ & Pnma & 5.49 & 4.4 & 7.42 & 158.3 & 3.10 & $\begin{array}{c}\text { This } \\
\text { work }\end{array}$ \\
\hline & & & & 5.45 & 4.43 & 7.47 & & & $\operatorname{cal}[31]$ \\
\hline \multirow[t]{2}{*}{$\mathrm{MgB}_{7}$} & 87.5 & $4 \mathrm{c}(0,0.5,0)$ & Imma & 10.47 & 5.97 & 8.11 & 198.2 & 3.56 & $\begin{array}{l}\text { This } \\
\text { work }\end{array}$ \\
\hline & & & & 10.48 & 5.97 & 8.12 & 206.5 & & $\operatorname{cal[21]}$ \\
\hline
\end{tabular}

The energy-volume $\mathrm{E}(\mathrm{V})$ relation curves at zero absolute temperature were obtained using the first-principle method, as shown in Figure 2. All the energy-volume data were fitted to the Birch-Murnaghan model as follows [32]:

$$
\mathrm{E}(V)=E_{0}+\frac{9 V_{0} B_{0}}{16}\left\{\left[\left(\frac{V_{0}}{V}\right)^{\frac{2}{3}}-1\right]^{3} B_{0}^{\prime}+\left[\left(\frac{V_{0}}{V}\right)^{\frac{2}{3}}-1\right]^{2}\left[6-4\left(\frac{V_{0}}{V}\right)^{\frac{2}{3}}\right]\right\}
$$

where $\mathrm{B}_{0}$ is the bulk modulus, $\mathrm{B}_{0}^{\prime}$ is the first pressure derivative of the bulk modulus, and $\mathrm{V}_{0}$ is the equilibrium volume.

$$
\mathrm{B}_{0}=-\mathrm{V}\left(\frac{\mathrm{d} P}{d V}\right)_{P=0}=V_{0}\left(\frac{d^{2} E(V)}{d^{2} V}\right)_{V_{0}} \quad \mathrm{~B}_{0}^{\prime}=-\left(\frac{d B}{d P}\right)_{P=0}
$$

The functional pressure-volume $\mathrm{P}(\mathrm{V})$ data were obtained after the fitting of the $\mathrm{E}(\mathrm{V})$ curves to the Birch-Murnaghan model; therefore, the $\mathrm{P}(\mathrm{V})$ curves displayed the relationship between the structural change and the pressure increase with a step of $10 \mathrm{GPa}$, as shown in Figure 3. Moreover, the $P(V)$ curves were calculated by using the equilibrium thermodynamic relation as follows [33]:

$$
\mathrm{P}(V)=\frac{3}{2} B_{0}\left(\left(\frac{V}{V_{0}}\right)^{-7 / 3}-\left(\frac{V}{V_{0}}\right)^{-5 / 3}\right)\left(1+\frac{3}{4}\left(B_{0} \cdot-4\right)\left(\left(\frac{V}{V_{0}}\right)^{-2 / 3}-1\right)\right)
$$



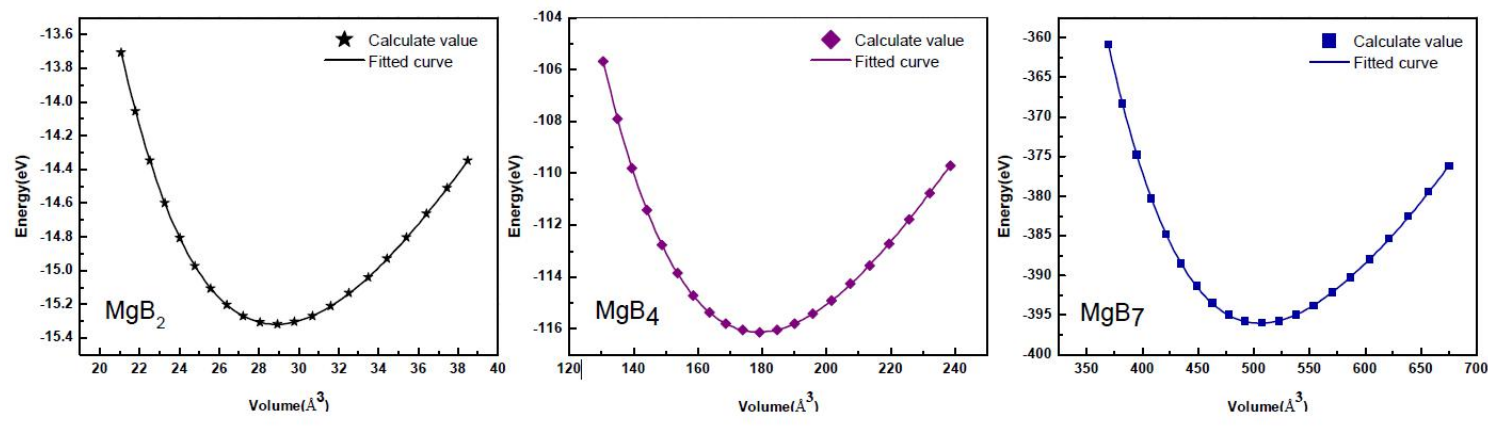

Figure 2. Variation between energy and volume of $\mathrm{Mg}-\mathrm{B}$ compounds.

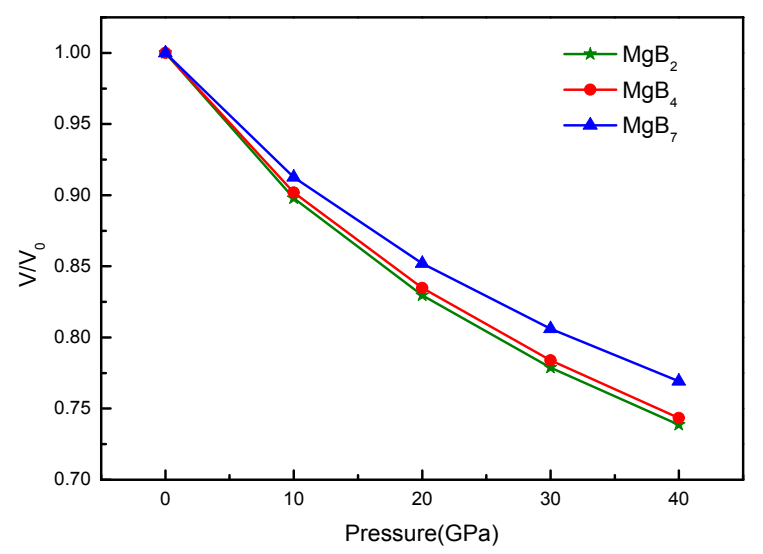

Figure 3. Volume ratio and pressure relation of $\mathrm{Mg}-\mathrm{B}$ compounds with an interval of 10GPa.

The volume ratio $\mathrm{V} / \mathrm{V}_{0}$ of the three $\mathrm{Mg}-\mathrm{B}$ compounds decreased with an increase in the pressure, as shown in Figure 3, which was in agreement with the general rules. Moreover, the value of $\mathrm{V} / \mathrm{V}_{0}$ of the $\mathrm{Mg}-\mathrm{B}$ compounds under the same pressure from $10 \mathrm{GPa}$ to $40 \mathrm{GPa}$ ranged in the following order: $\mathrm{MgB}_{7}<\mathrm{MgB}_{4}<\mathrm{MgB}_{2}$. That is, $\mathrm{MgB}_{7}$ was harder to compress under the same applied pressure, as it had the lowest value of $\mathrm{V} / \mathrm{V}_{0}$ among the three $\mathrm{Mg}-\mathrm{B}$ compounds; furthermore, $\mathrm{MgB}_{2}$ was the most sensitive to the pressure-volume relationship.

\subsection{Mechanical properties}

The elastic constants $\left(\mathrm{C}_{\mathrm{ij}}\right)$ of the crystal as an indispensable parameter played an important role in characterising the mechanical behaviours, because it contains a significant mechanical information under various pressures. There were nine $\left(\mathrm{C}_{11}, \mathrm{C}_{12}, \mathrm{C}_{13}, \mathrm{C}_{22}, \mathrm{C}_{23}, \mathrm{C}_{33}, \mathrm{C}_{44}, \mathrm{C}_{55}\right.$, and $\left.\mathrm{C}_{66}\right)$ elastic constants for the orthorhombic crystals of $\mathrm{MgB}_{4}$ and $\mathrm{MgB}_{7}$, and six elastic constants $\left(\mathrm{C}_{11}, \mathrm{C}_{12}, \mathrm{C}_{13}, \mathrm{C}_{33}, \mathrm{C}_{44}\right.$, and $\left.\mathrm{C}_{66}\right)$ for the hexagonal crystal of $\mathrm{MgB}_{2}$. Table 2 shown the simulated elastic constants and other elastic parameters of the $\mathrm{Mg}-\mathrm{B}$ compounds; they were in agreement with the reference data. Moreover, the mechanical stability criterion of the hexagonal and orthorhombic structures of the $\mathrm{Mg}-\mathrm{B}$ compounds is listed below:

Table 2. Elastic constants $\mathrm{C}_{\mathrm{ij}}(\mathrm{GPa})$ and elastic moduli B, G, and $\mathrm{E}(\mathrm{GPa})$ of $\mathrm{Mg}$-B compounds at $0 \mathrm{GPa}$ along with the reported data.

\begin{tabular}{cccccccccccccc}
\hline Phase & Species & $\mathbf{C}_{11}$ & $\mathbf{C}_{22}$ & $\mathrm{C}_{33}$ & $\mathrm{C}_{12}$ & $\mathrm{C}_{13}$ & $\mathrm{C}_{23}$ & $\mathbf{C}_{44}$ & $\mathrm{C}_{55}$ & $\mathrm{C}_{66}$ & $\mathbf{B}$ & $\mathrm{G}$ & $\mathrm{E}$ \\
\hline $\mathrm{MgB}_{2}$ & Present & 419.8 & & 253.6 & 53.2 & 41.5 & & 184.3 & 64.6 & & 151.7 & 116.2 & 276.1 \\
& Cal[30] & 432.0 & 254.3 & 61.0 & 41.0 & & 185.1 & 71.3 & & 157.0 & 116.9 & 277.6 \\
$\mathrm{MgB}_{4}$ & Present & 231.4 & 289.6 & 493.5 & 22.8 & 162.9 & 41.3 & 96.8 & 108.6 & 173.5 & 158.3 & 112.4 & 272.7 \\
$\mathrm{MgB}_{7}$ & Present & 536.5 & 530.6 & 500.3 & 60.8 & 42.1 & 45.1 & 194.3 & 221.3 & 248.7 & 205.8 & 225.9 & 496.2 \\
& Cal[21] & 539 & 527.7 & 496.9 & 61.1 & 42.4 & 44.8 & 195.1 & 220.6 & 250.1 & 206.5 & 226.6 & 497.7 \\
\hline
\end{tabular}


For the hexagonal $\left(\mathrm{MgB}_{2}\right)$ crystal [34]:

$$
\mathrm{C}_{44}>0, \mathrm{C}_{11}>\left|\mathrm{C}_{12}\right|, \quad\left(C_{11}+2 C_{12}\right) C_{33}-2 C_{13}^{2}>0
$$

For the orthorhombic $\left(\mathrm{MgB}_{4}\right.$ and $\left.\mathrm{MgB}_{7}\right)$ crystal [35]:

$$
\begin{gathered}
\mathrm{C}_{\mathrm{ii}}>0, i=1 \sim 6, \mathrm{C}_{11}+\mathrm{C}_{22}>2 \mathrm{C}_{12}, \mathrm{C}_{11}+\mathrm{C}_{33}>2 \mathrm{C}_{13} \\
\mathrm{C}_{22}+\mathrm{C}_{33}>2 C_{23}, \mathrm{C}_{11}+\mathrm{C}_{22}+\mathrm{C}_{33}+2\left(\mathrm{C}_{12}+\mathrm{C}_{13}+\mathrm{C}_{23}\right)>0
\end{gathered}
$$

The influence of the applied pressure from $0 \mathrm{GPa}$ to $40 \mathrm{GPa}$ on the calculated elastic constants for the Mg-B compounds is displayed in Figure 4. As shown in Figure 4, the entries in the elastic tensor $C_{i j}$ increased with an increase in pressure in the range from 0 to $40 \mathrm{GPa}$, and when the pressure reached to $40 \mathrm{GPa}$, all the elastic constants are well matched with the criterion of mechanical stability. Moreover, the deformation resistance of $\mathrm{MgB}_{2}$ and $\mathrm{MgB}_{7}$ is highest in the $\mathrm{x}$-axis direction than in that of the other axes; this might be attributed to the fact that the largest elastic constant of $C_{11}$ was observed for $\mathrm{MgB}_{2}$ and $\mathrm{MgB}_{7}$. Similarly, the $\mathrm{C}_{22}$ of $\mathrm{MgB}_{4}$ with the largest elastic constant indicated that the $\mathrm{y}$-axis had the highest deformation resistance for $\mathrm{MgB}_{4}$. According to the existing literature [36], the values of $\mathrm{C}_{44}, \mathrm{C}_{55}$, and $\mathrm{C}_{66}$ are always used to represent the ability of compounds to resist shear deformation. Therefore, $\mathrm{MgB}_{7}$ had higher values of $\mathrm{C}_{44}$ and $\mathrm{C}_{66}$ than the other two $\mathrm{Mg}-\mathrm{B}$ compounds, according to Figure 4, which implied that $\mathrm{MgB}_{7}$ had the highest resistance ability for the shear deformation.

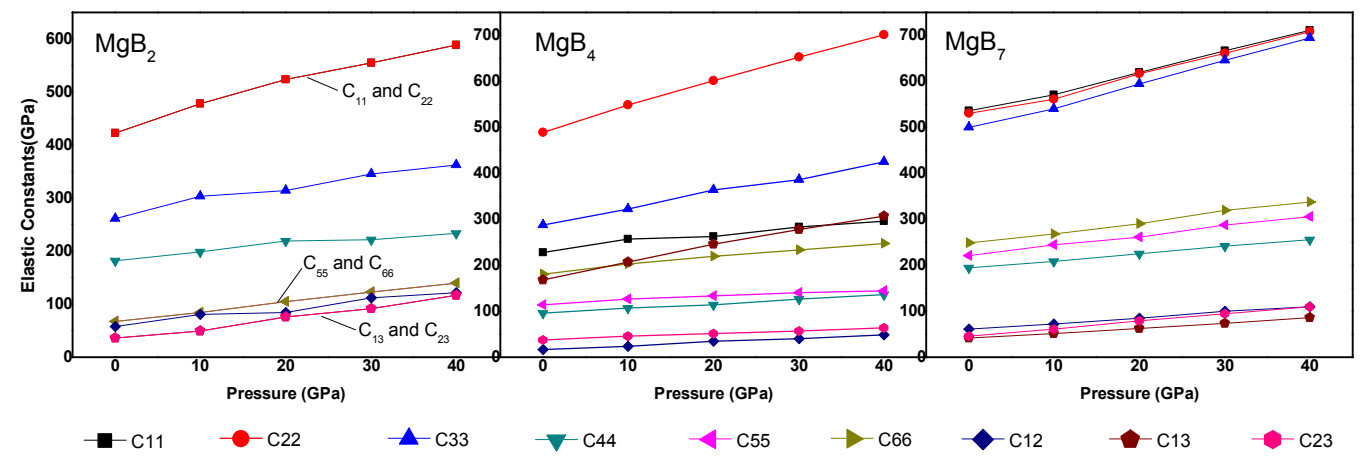

Figure 4. Pressure dependence of the elastic constants of the three $\mathrm{Mg}$-B compounds.

Generally, the elastic modulus contained B, G, and E could be subsequently obtained by using the VRH (Voigt-Reuss-Hill) approximation [37], after the elastic constants $C_{i j}$ were obtained. The calculation equations are given by [38-39]:

$$
\mathrm{B}_{\mathrm{H}}=\frac{1}{2}\left(\mathrm{~B}_{\mathrm{V}}+\mathrm{B}_{\mathrm{R}}\right) \quad \mathrm{G}_{\mathrm{H}}=\frac{1}{2}\left(\mathrm{G}_{\mathrm{V}}+\mathrm{G}_{\mathrm{R}}\right) \quad \mathrm{E}=\frac{9 \mathrm{BG}}{3 \mathrm{~B}+\mathrm{G}}
$$

For the hexagonal crystal:

$$
\begin{gathered}
\mathrm{B}_{\mathrm{V}}=\frac{2}{9}\left(\mathrm{C}_{11}+\mathrm{C}_{12}+2 \mathrm{C}_{13}+\frac{1}{2} \mathrm{C}_{33}\right) \\
\mathrm{G}_{\mathrm{V}}=\frac{1}{15}\left(2 \mathrm{C}_{11}+\mathrm{C}_{33}-\mathrm{C}_{12}-2 \mathrm{C}_{13}\right)+\frac{1}{5}\left(2 \mathrm{C}_{44}+\mathrm{C}_{66}\right)
\end{gathered}
$$




$$
\begin{gathered}
\mathrm{B}_{\mathrm{R}}=\frac{\left(\mathrm{C}_{11}+\mathrm{C}_{12}\right) \mathrm{C}_{33}-2 \mathrm{C}_{13}^{2}}{\mathrm{C}_{11}+C_{12}-4 C_{13}+2 C_{33}} \\
\mathrm{G}_{\mathrm{R}}=\frac{5 \mathrm{C}^{2} \mathrm{C}_{44} \mathrm{C}_{66}}{2\left[3 \mathrm{~B}_{\mathrm{V}} \mathrm{C}_{44} \mathrm{C}_{66}+\mathrm{C}^{2}\left(\mathrm{C}_{44}+\mathrm{C}_{66}\right)\right]} \\
\mathrm{C}^{2}=\left(\mathrm{C}_{11}+\mathrm{C}_{12}\right) \mathrm{C}_{33}-2 \mathrm{C}_{13}^{2}
\end{gathered}
$$

For an orthorhombic crystal:

$$
\begin{gathered}
\mathrm{B}_{\mathrm{v}}=\frac{1}{9}\left[\mathrm{C}_{11}+C_{22}+C_{33}+2\left(C_{12}+C_{13}+C_{23}\right)\right] \\
\mathrm{G}_{\mathrm{v}}=\frac{1}{15}\left[\mathrm{C}_{11}+\mathrm{C}_{22}+C_{33}+3\left(C_{44}+C_{55}+\mathrm{C}_{66}\right)-\left(C_{12}+C_{13}+C_{23}\right)\right] \\
\mathrm{B}_{\mathrm{R}}=\Delta /\left[\mathrm{C}_{11}\left(\mathrm{C}_{22}+C_{33}-2 C_{23}\right)+C_{22}\left(C_{33}-2 C_{13}\right)-2 C_{33} C_{12}\right. \\
\left.+C_{12}\left(2 C_{23}-C_{12}\right)+C_{13}\left(2 C_{12}-C_{13}\right)+C_{23}\left(2 C_{13}-C_{23}\right)\right] \\
\mathrm{G}_{\mathrm{R}}=15\left\{4 \left[C_{11}\left(C_{22}+C_{33}+C_{23}\right)+C_{22}\left(C_{33}+C_{13}\right)+C_{33} C_{12}-\mathrm{C}_{12}\left(\mathrm{C}_{23}+\mathrm{C}_{12}\right)\right.\right. \\
\left.\left.-\mathrm{C}_{13}\left(\mathrm{C}_{12}+\mathrm{C}_{13}\right)-\mathrm{C}_{23}\left(\mathrm{C}_{13}+\mathrm{C}_{23}\right)\right] / \Delta+3\left(\frac{1}{C_{44}}+\frac{1}{C_{55}}+\frac{1}{C_{66}}\right)\right\} \\
\Delta=\mathrm{C}_{13}\left(C_{12} C_{23}-C_{13} C_{22}\right)+\mathrm{C}_{23}\left(C_{12} C_{13}-C_{23} C_{11}\right)+C_{33}\left(C_{11} C_{22}-C_{12}^{2}\right)
\end{gathered}
$$

As displayed in Figure 5, the elastic moduli consisting of bulk modulus B, shear modulus G, and Young's modulus E increased linearly with an increase in the pressure, which indicated that the resistance to the volume deformation increased. From the reports, we inferred that the higher the bulk modulus was, the better was the resistance to deformation [40]. Simultaneously, we found that $\mathrm{MgB}_{7}$ had a stronger capacity to resist volume deformation and had higher hardness, as it had the highest values of the elastic moduli than the others at a constant pressure. From Figure 5, we inferred that the volume deformation resistance ability under a pressure from $0 \mathrm{GPa}$ to $30 \mathrm{GPa}$ deferred to the following increased order: $\mathrm{MgB}_{2}<\mathrm{MgB}_{4}<\mathrm{MgB}_{7}$. Nevertheless, the ability resist to the volume change of $\mathrm{MgB}_{2}$ was stronger than others under pressures of $30-40 \mathrm{GPa}$, and its $\mathrm{G}$ and $\mathrm{E}$ were larger than $\mathrm{MgB}_{4}{ }^{\prime} \mathrm{s}$. Therefore, it would be inaccurate to predict the hardness $\mathrm{of}^{\mathrm{MgB}} \mathrm{B}_{2}$ and $\mathrm{MgB}_{4}$.

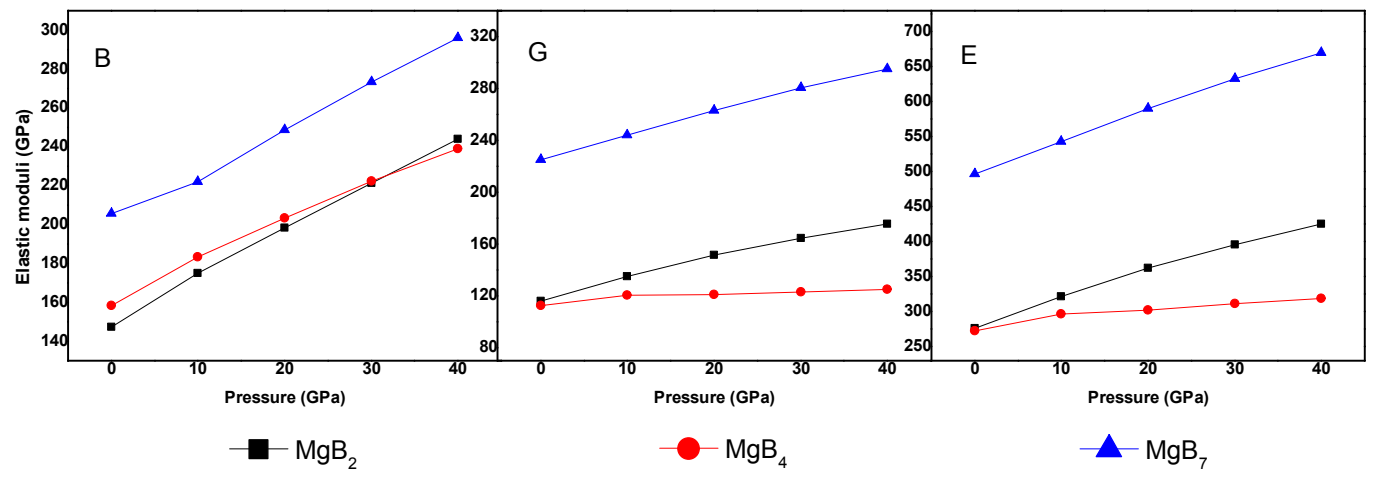

Figure 5. Elastic modulus ( $\mathrm{B}, \mathrm{G}$, and $\mathrm{E}$ ) of $\mathrm{Mg}-\mathrm{B}$ compounds various from different pressure.

In general, the $\mathrm{B} / \mathrm{G}$ ratio and Poisson's ratio $v$ can be used to explain the ductility and the brittleness of Mg-B compounds [41-42]. Figure 6 presents the relation between the B/G ratio and 
Poisson's ratio of Mg-B compounds under changed pressure. Poisson's ratio $v$ can be calculated as follows:

$$
v=\frac{3 B-2 G}{6 B+2 G}
$$

The $\mathrm{B} / \mathrm{G}$ ratio and $v$ were proposed to describe the brittle or ductile of materials, when the values were 1.75 and 0.26 , respectively. As shown in Figure 6, the Poisson's ratio $v$ and B/G ratio of $\mathrm{MgB}_{4}$ were 0.267 and 1.80 at $30 \mathrm{GPa}$ and 0.277 and 1.91 at $40 \mathrm{GPa}$, respectively. Thus, $\mathrm{MgB}_{4}$ showed ductile behaviour under pressures of $30-40 \mathrm{GPa}$, but brittle behaviour at 0-30 GPa, illustrating that the ductile transition for $\mathrm{MgB}_{4}$ occurred when the pressure increased to $30 \mathrm{GPa}$. Nevertheless, $\mathrm{MgB}_{2}$ and $\mathrm{MgB}_{7}$ displayed a brittle nature, and the brittleness of $\mathrm{Mg}-\mathrm{B}$ compounds could be ranked in the following order: $\mathrm{MgB}_{4}<\mathrm{MgB}_{2}<\mathrm{MgB}_{7}$. Moreover, all the $\mathrm{B} / \mathrm{G}$ ratios and $v$ values increased with an increase in the pressure, indicating that the ductility could be improved by increasing the applied pressure on the $\mathrm{Mg}-\mathrm{B}$ compounds.

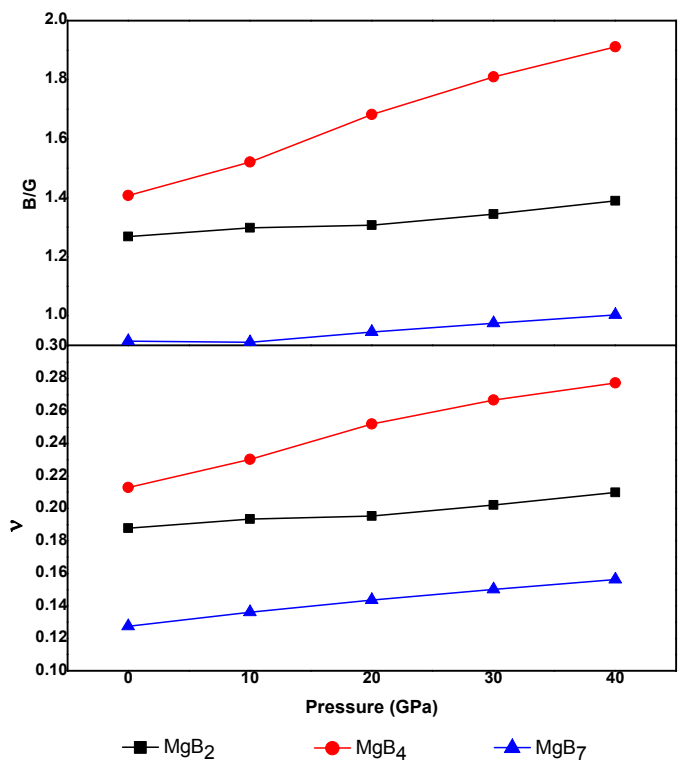

Figure 6. Pressures dependence of the B/G ratio and Poisson's ratio v.

The hardness $\mathrm{H}$ is an important parameter to measure the structure and mechanical properties, which can be calculated by using the following semi-empirical law [43]:

$$
\mathrm{H}=\frac{(1-2 \mathrm{v}) E}{6(1+v)}=\frac{\mathrm{G}^{*} E}{9 B}
$$

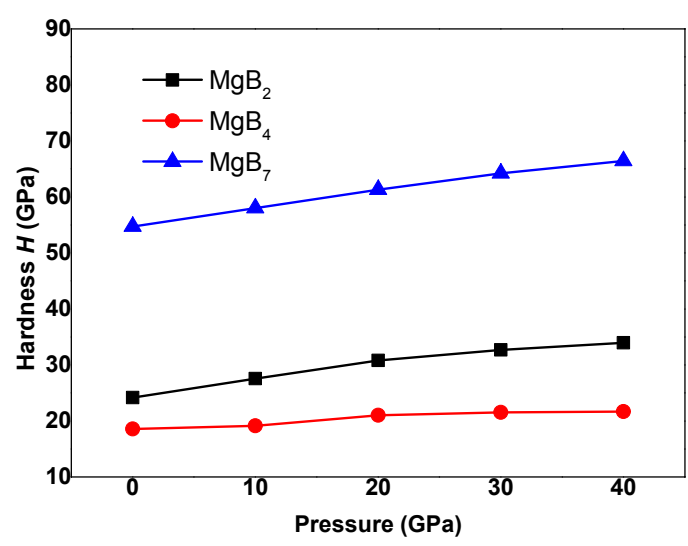


Figure 7. Variation of micro-hardness at various pressures.

As shown in Figure 7, the hardness of $\mathrm{Mg}$-B compounds increased with an increase in the external pressure, and the values of hardness could be rowed as the following order: $\mathrm{MgB}_{7}>\mathrm{MgB}_{2}>$ $\mathrm{MgB}_{4}$, which implied that $\mathrm{MgB}_{7}$ had the highest hardness; this finding matched well with the above mentioned results. On the basis of a comparison with Figure 5, we can summarised that the effects of $G$ and $E$ on the hardness was greater than $B$.

Elastic anisotropy plays an important role in crack behaviour and phase transformations, and its formula is defined as follows [44]:

$$
\mathrm{A}^{\mathrm{U}}=5 \frac{\mathrm{G}_{\mathrm{V}}}{G_{R}}+\frac{B_{V}}{B_{R}}-6
$$

As listed in Table 3, all the predicted values of $A_{U}$ were greater than zero, which implied that all the three Mg-B compounds were anisotropic materials. Moreover, the values of $\mathrm{A}_{U}$ of $\mathrm{MgB}_{4}$ increased with an increase in the applied pressure, indicating that the anisotropy of $\mathrm{MgB}_{4}$ was enhanced by the increase in the applied pressure. Moreover, the elastic anisotropy of $\mathrm{MgB}_{4}$ was more sensitive to pressure according to the increase in the values of $A_{\mathrm{U}}$, and the anisotropy from low to high could be ranked in the following order: $\mathrm{MgB}_{7}<\mathrm{MgB}_{2}<\mathrm{MgB}_{4}$.

Table 3. Universal anisotropy $\mathrm{A}_{\mathrm{U}}$ of $\mathrm{Mg}-\mathrm{B}$ binary compounds at external pressure.

\begin{tabular}{ccccc}
\hline $\begin{array}{c}\text { Universal } \\
\text { anisotropy }\end{array}$ & $\begin{array}{c}\text { Pressure } \\
(\mathbf{G P a})\end{array}$ & $\mathbf{M g B}_{2}$ & $\mathbf{M g B}_{4}$ & $\mathbf{M g B}_{7}$ \\
\hline $\mathrm{A}^{\mathrm{U}}(\mathrm{GPa})$ & 0 & 1.231 & 1.865 & 0.153 \\
& 10 & 0.910 & 1.987 & 0.131 \\
& 20 & 0.690 & 2.151 & 0.118 \\
& 30 & 0.466 & 2.236 & 0.108 \\
& 40 & 0.393 & 2.362 & 0.104 \\
\hline
\end{tabular}

\subsection{Electronic properties and band structure}

To determine the effects of pressure on the mechanical properties and gain in-depth knowledge of the electronic structure of Mg-B compounds, the partial density of states (PDOS) and the total density of states (TDOS) under various pressures are shown in Figure 8. Figures 8(a), 8(b), and 8(c) show that the $\mathrm{MgB}_{2}$ presented many peak point near the Fermi level, this indicated that $\mathrm{MgB}_{2}$ exhibited its special electrical conductivity, but the Fermi level of $\mathrm{MgB}_{4}$ and $\mathrm{MgB}_{7}$ are both in the range of zero DOS value, which implied that $\mathrm{MgB}_{4}$ and $\mathrm{MgB}_{7}$ may present semiconductor or insulator characteristics. Moreover, the primary bond peaks near the Fermi level were mainly occupied by the B $2 p$ states and $\mathrm{Mg} 3 \mathrm{p}$ states for $\mathrm{MgB}_{2}, \mathrm{MgB}_{4}$, and $\mathrm{MgB}_{7}$. It can be seen from the Figure 8, the DOS values of $\mathrm{MgB}_{4}$ and $\mathrm{MgB}_{7}$ at the Fermi level are all above 0, which implies that both of $\mathrm{MgB}_{4}$ and $\mathrm{MgB}_{7}$ also present metallic properties. However, for the $\mathrm{MgB}_{7}$, the valence band from 2.0 to $5.0 \mathrm{eV}$, Mg-p band contributes less than the Mg-s band near the Fermi level, The s-p hybridization between the $\mathrm{B}$ and $\mathrm{Mg}$ atoms forms covalent bonding for $\mathrm{MgB}_{7}$. Figures $8(\mathrm{~d}), 8(\mathrm{e})$, and $8(\mathrm{f})$ only depict the TDOS of the $\mathrm{Mg}-\mathrm{B}$ compounds at $0 \mathrm{GPa}, 20 \mathrm{GPa}$, and $40 \mathrm{GPa}$, to demonstrate the regularity of TDOS for Mg-B compounds under various pressures. They show that there was a slight decrease in TDOS with an increase in the external pressure, which indicated that there was no structural phase transformation and small interaction potentials changed because of the decrease in the atomic distance under pressure. These figures also display the structural stability and the various electronic characteristics of $\mathrm{Mg}-\mathrm{B}$ compounds under applied pressure. 

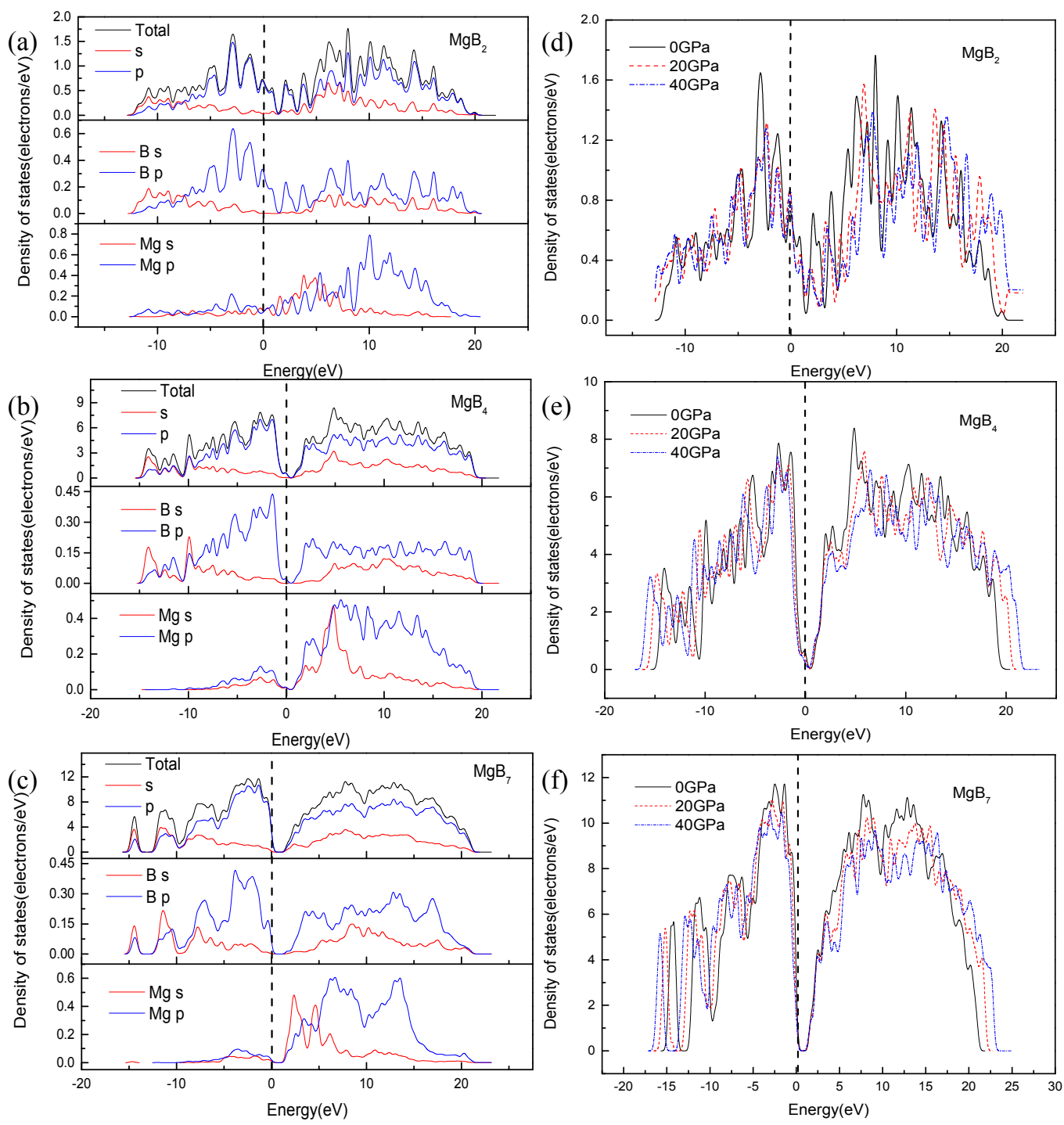

Figure 8. Density of states of $\mathrm{Mg}-\mathrm{B}$ compounds, (a), (b), and (c) are partial density of states for $\mathrm{MgB}_{2}$, $\mathrm{MgB}_{4}$, and $\mathrm{MgB}_{7}$, respectively; (d), (e), and (f) are total density of states under various pressures for $\mathrm{MgB}_{2}, \mathrm{MgB}_{4}$, and $\mathrm{MgB}_{7}$, respectively.

\subsection{Thermodynamic properties}

The quasi-harmonic Debye model of the phonon density of states was implemented in this part of the study to investigate the thermodynamic behaviours of the $\mathrm{Mg}$-B compounds under pressure, namely the heat capacity $C_{v}, C_{p}$, the linear thermal expansion coefficient, and the Debye temperature $\Theta \mathrm{D}$ of the $\mathrm{Mg}-\mathrm{B}$ compounds. The above-obtained $\mathrm{E}(\mathrm{V})$ curves, as important input data for numerical minimisation programs in this model, were used to obtain more thermodynamical information of the Mg-B compounds [45-46]. Moreover, the vibrational thermodynamic properties were obtained at a designated temperature in the quasi-harmonic Debye model; this might be attributed to the consideration of the vibrational contribution for the internal energy. To improve the calculated precision of the thermodynamic behaviours, the 21 volume points from $0.90 \mathrm{a}$ to $1.10 \mathrm{a}$ of the calculated energy-volume were implied .

The Debye temperature of the $\mathrm{Mg}-\mathrm{B}$ compounds was calculated from the average sound velocity by using the following formula [47]: 


$$
\begin{gathered}
\Theta \mathrm{D}=\frac{\mathrm{h}}{k_{B}}\left[\frac{3 n}{4 \pi}\left(\frac{N_{A} \rho}{M}\right)\right]^{1 / 3} v_{m} \\
v_{\mathrm{m}}=\left[\frac{1}{3}\left(\frac{2}{v_{s}^{3}}+\frac{1}{v_{l}^{3}}\right)\right]^{-1 / 3} \quad v_{\mathrm{s}}=\sqrt{\frac{G}{\rho}} \quad v_{l}=\sqrt{\frac{3 B+4 G}{3 \rho}}
\end{gathered}
$$

where $v_{\mathrm{m}}, v_{\mathrm{s}}$, and $v_{1}$ represent the average wave velocity and the shear and longitudinal sound velocities, respectively; $h$ is Planck's constant; $k_{B}$ is Boltzmann's constant; $n$ is the total number of atoms; $\mathrm{N}_{\mathrm{A}}$ is Avogadro's number; $\mathrm{Q}$ is the density; and $\mathrm{M}$ is the molecular weight. As shown in Figure 9, the $\mathrm{\Theta D}$ of the Mg-B compounds increased with an increase in the pressure and remained almost constant from 0 to $200 \mathrm{~K}$ but linearly decreased after $200 \mathrm{~K}$. Simultaneously, the $\Theta \mathrm{D}$ of the $\mathrm{Mg}-\mathrm{B}$ compounds from low to high could be rowed as the following order: $\mathrm{MgB}_{2}<\mathrm{MgB}_{4}<\mathrm{MgB}_{7}$, when all the compounds were under the same temperature and pressure conditions.
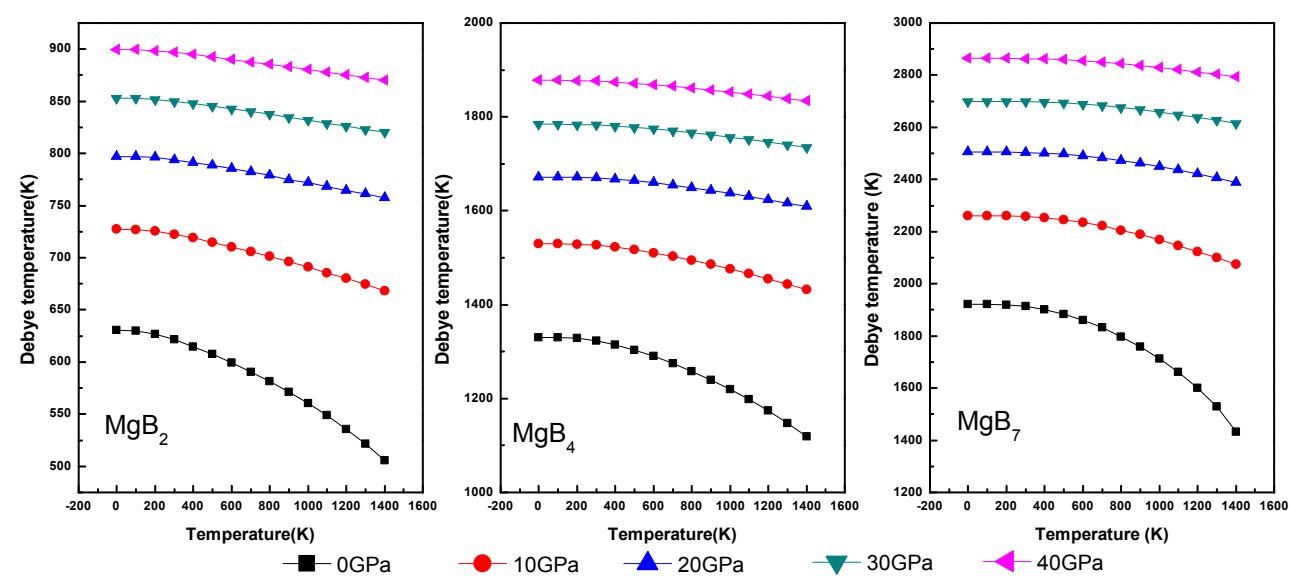

Figure 9. Debye temperature of Mg-B compounds under various pressure and temperature.

Figure 10 shows the temperature and pressure dependence of the linear thermal expansion coefficient $\alpha$ of the Mg-B compounds. The thermal expansion coefficient is defined as $\alpha=\frac{1}{\mathrm{~V}} \frac{\partial \mathrm{V}}{\partial \mathrm{T}}$, and the thermal expansion coefficient $\alpha$ increased with an increase in the pressure and the temperature. Although $\alpha$ was linear with $\mathrm{T}^{3}$ in the range from 0 to $300 \mathrm{~K}, \alpha$ presented a gradual growth rate and changed gently when the temperature exceeded $300 \mathrm{~K}$, which implied that the main thermal expansion of the Mg-B compounds occurred in the low-temperature region. In addition, $\alpha$ presented a decreasing tendency when the pressure increased to $40 \mathrm{GPa}$ at a constant temperature. Meanwhile, the impact strength of pressure on the linear thermal expansion coefficient increased when the pressure was above $20 \mathrm{GPa}$.

The heat capacity are estimated by using Debye temperature and electronic structures of Mg-B compounds, which defined as follows:

$$
\begin{gathered}
\mathrm{C}_{\mathrm{V}}=3 n k\left[4 D\left(\frac{\Theta}{T}\right)-\frac{3 \Theta / T}{e^{\Theta / T}-1}\right] \\
\mathrm{C}_{\mathrm{P}}=\frac{\pi^{2} \mathrm{~K}_{\mathrm{B}}^{2} \mathrm{D}_{\mathrm{f}} T}{3}+\frac{12 \pi^{4} R n T^{3}}{5 \theta_{D}^{3}}, \gamma=\frac{\pi^{2} \mathrm{~K}_{\mathrm{B}}^{2} \mathrm{D}_{\mathrm{f}}}{3}, \beta=\frac{12 \pi^{4} R n}{5 \theta_{D}^{3}}
\end{gathered}
$$

Where $\gamma$ and $\beta$ are the electronic and phonon contributions to the specific heat respectively. 
The temperature and the pressure dependence of the isochoric heat capacity $\left(\mathrm{C}_{\mathrm{V}}\right)$ and the isobaric heat capacity $\left(\mathrm{C}_{\mathrm{P}}\right)$ of the $\mathrm{Mg}-\mathrm{B}$ compounds are displayed in Figure 10. When the temperature was below $300 \mathrm{~K}$, the variation of $C_{V}$ and $C_{P}$ exhibited an obvious and sharp rise; this subordinated Debye's law. However, $C_{P}$ and $C_{V}$ were likely to continue to increase and remained constant after $300 \mathrm{~K}$, respectively, due to the $\mathrm{C}_{\mathrm{V}}$ abided by the Dulong-Petit limit under high temperature conditions. Moreover, both the isochoric heat capacity $\left(C_{V}\right)$ and the isobaric heat capacity $\left(C_{\mathrm{P}}\right)$ decreased with an increase in the pressure. Thus, from Figure 11, we inferred that the heat capacity of $\mathrm{MgB}_{7}$ was higher than that of $\mathrm{MgB}_{4}$ and $\mathrm{MgB}_{2}$, indicating the stronger ability of release and absorption energy of $\mathrm{MgB}_{7}$.
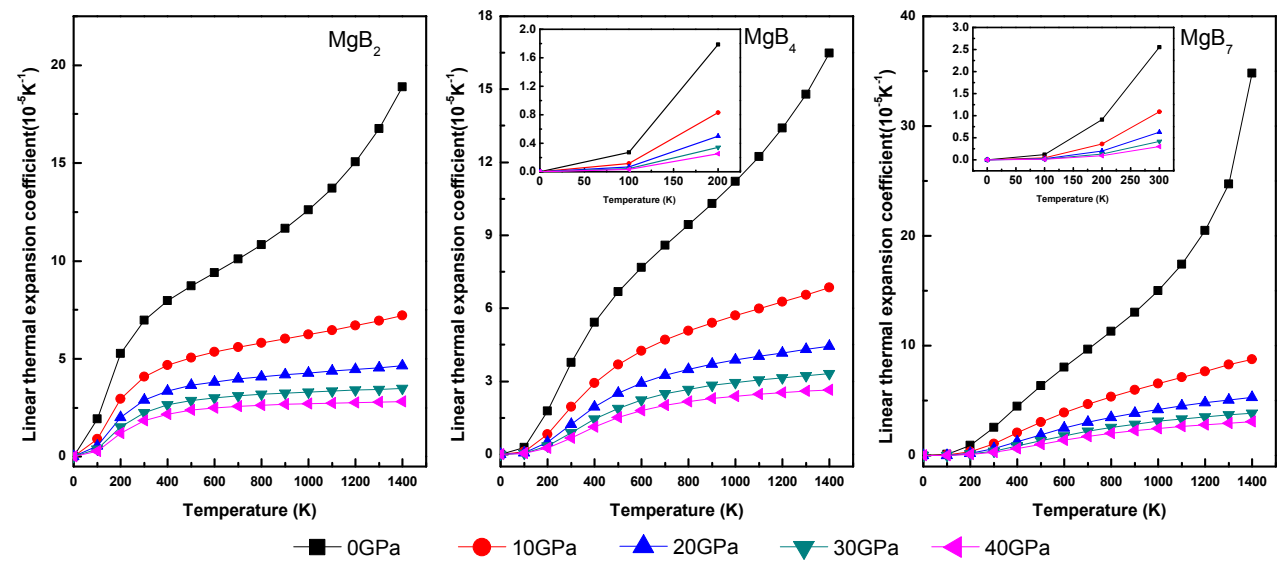

Figure 10. Linear thermal expansion coefficient of $\mathrm{Mg}-\mathrm{B}$ compounds as function of pressure and temperature.
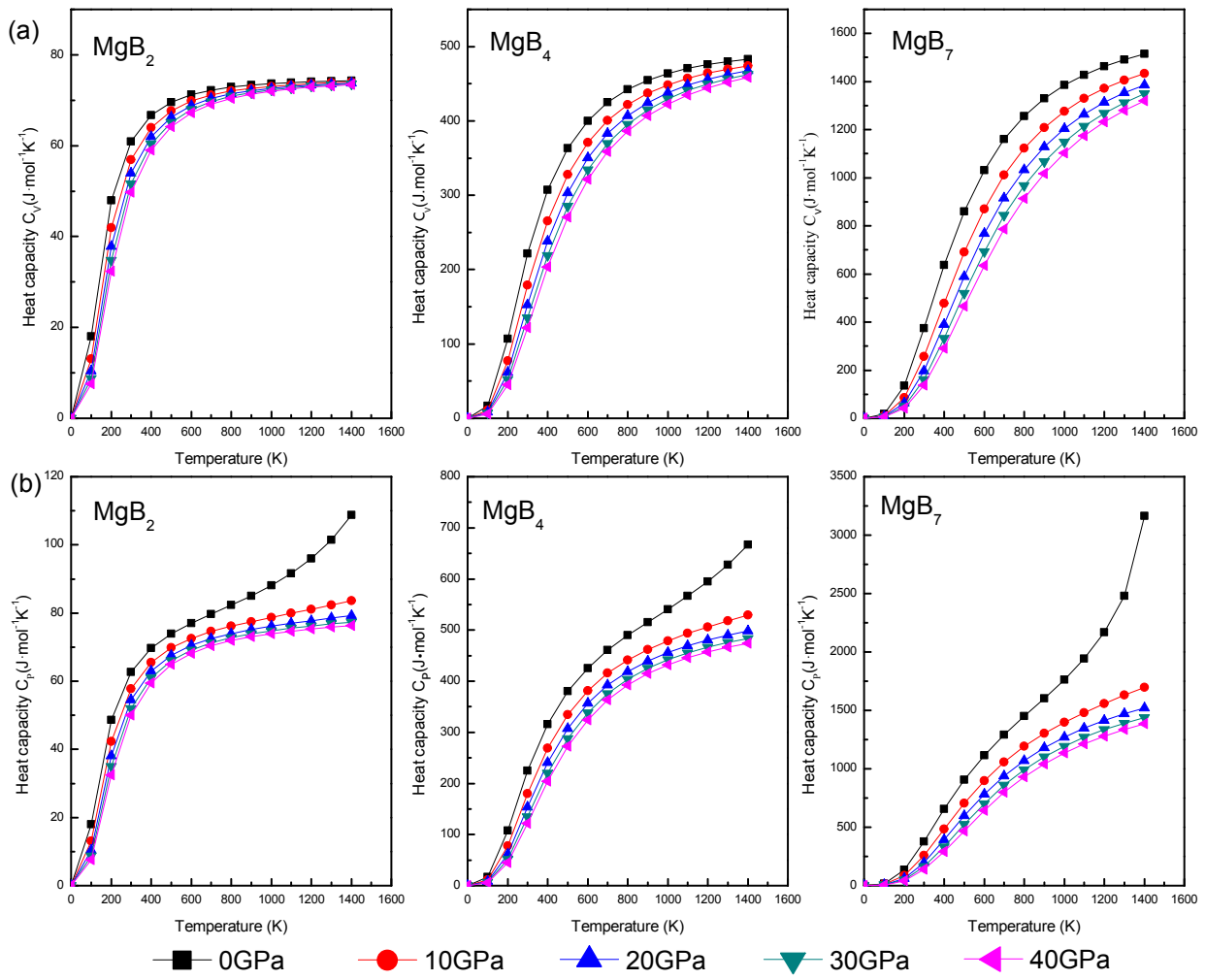

Figure 11. Pressure and temperature dependence of heat capacity $C_{V}, C_{P}$ of Mg-B compounds.

\section{Conclusion}


In this investigation, the structural, mechanical, electronic, and thermodynamic properties of Mg-B compounds were studied by using density functional theory; the conclusions of this paper can be summarized as follows:

(1) The simulated elastic constants and elastic modulus through first-principle method are well coincided with the experimental values and theoretical calculations. The ratio of $\mathrm{V} / \mathrm{V}_{0}$ decreased with an increase in the external pressure and increased with an increase in the boron content.

(2) The three Mg-B compounds are mechanically stable from 0GPa to 40GPa. The additional pressure on $\mathrm{MgB}_{2}, \mathrm{MgB}_{4}$, and $\mathrm{MgB}_{7}$ can improve it's $\mathrm{B}, \mathrm{G}$, and $\mathrm{E}$, which rowed as the following order: $\mathrm{MgB}_{2}<\mathrm{MgB}_{4}<\mathrm{MgB}_{7}$, but these properties of $\mathrm{MgB}_{2}$ is more excellent than that of $\mathrm{MgB}_{4}$ when the pressure reach to $30 \mathrm{GPa}$. Besides, a ductile conversion behavior at $30 \mathrm{GPa}$ is found in the process of increasing the pressure for $\mathrm{MgB}_{4}$.

(3) The hardness of three $\mathrm{Mg}-\mathrm{B}$ compounds enhanced with the increased pressure, the hardness of $\mathrm{Mg}-\mathrm{B}$ compounds could be rowed as following order: $\mathrm{MgB}_{7}>\mathrm{MgB}_{2}>\mathrm{MgB}_{4}$. Conversely, the calculated elastic anisotropy could be ranked as following order: $\mathrm{MgB}_{7}<\mathrm{MgB}_{2}<\mathrm{MgB}_{4}$.

(4) From the results the total density of states(TDOS) and the partial density of states (PDOS), the main orbital hybridizations of $\mathrm{Mg}-\mathrm{B}$ compounds are $\mathrm{B} \mathrm{p}$ and $\mathrm{Mg} \mathrm{d}$ orbitals, $\mathrm{B} \mathrm{p}$ and $\mathrm{Mg} \mathrm{s}$ orbitals and $\mathrm{B} p$ and $\mathrm{Mg} p$ orbitals for $\mathrm{MgB}_{2}, \mathrm{MgB}_{4}$ and $\mathrm{MgB}_{7}$, respectively. There has no phase transformation under the rising external pressure. From the band structure, the $\mathrm{MgB}_{7}$ and the $\mathrm{MgB}_{4}$ shows semiconductor properties, but $\mathrm{MgB}_{2}$ presents excellent conductivity characteristic.

(5) The Debye temperature of all $\mathrm{Mg}-\mathrm{B}$ compounds reduce with an increase temperature from 0 to $1400 \mathrm{~K}$ but increase with an increase pressure from 0 to 40GPa. The linear thermal expansion coefficient $\alpha$ increase linearly with an increase temperature and pressure, while it present a sharp increase when the pressure is rising up to 40GPa. The results of the isochoric heat capacity $\left(C_{V}\right)$ and the isobaric heat capacity $\left(C_{P}\right)$ increase gradually with an increase temperature, while the $C_{V}$ remain unchanged at higher temperature due to followed the Dulong-Petit limit.

\section{Compliance with Ethical Standards}

This work is supported by the Natural Science Foundation of Shanxi province (Nos.201801D121111); The Natural Science Foundation of Shanxi province (Nos.201801D121108).

\section{Author Contributions statement}

Guowei Zhang and Chao Xu: Conceptualization, Methodology, Software, Hong $\mathrm{Xu}$ and Yuhong Zhao: Visualization and Supervision. Ying Dong: Editing. Fenger Sun and Xiaoyan Ren: Investigation. Mingjie Wang: Writing- Reviewing, Investigation and Editing.

\section{Competing Interests information}

Author Mingjie Wang, Guowei Zhang, Hong Xu, Ying Dong, Fenger Sun, Xiaoyan Ren, Yizheng Fu and Yuhong Zhao has both received research grants from North university of china. We declare that we have no financial and personal relationships with other people or organizations that can inappropriately influence our work, the authors declare that they have no conflict of interest.

\section{Data Availability Statement}

Some or all data, models, or code generated or used during the study are proprietary or confidential in nature and may only be provided with restrictions .

\section{References}


[1]. Lina. Yang, Wenbo. Wang, Mao. Wen, Jia. Wang, Xuan. Dai, Xinlei Gu and Kan. Zhang, Ultrafine nanocrystalline microstructure in Mg-B alloy for ultrahigh hardness and good ductility. Applied Surface Science. 486(2019) 102-107. doi: 10.1016/j.apsusc.2019.05.006.

[2]. RV. Chepulskii and Stefano Curtarolo, First-principles solubilities of alkali and alkaline-earth metals in Mg-B alloys, Physical Review. Series B. 79 (13) (2001) 134203. doi:10.1103/PhysRevB. 79. 134203.

[3]. A.Serquis, L.Civale, DL. Hammon, JY. Coulter, XZ. Liao, YT. Zhu, DE. Peterson and FM. Mueller, Microstructure and high critical current of powder in tube $\mathrm{MgB}_{2}$. Applied Physics Letters. 82(11) (2002) 1754-1756. doi:10.1063/1.1561572.

[4]. Alapati SV, Johnson JK, Sholl DS. Identification of destabilized metal hydrides for hydrogen storage using first principles calculations. Journal of Physical Chemistry B. 110 (17) (2006) 8769-8776. doi:10.1021/jp060482m.

[5]. Pediaditakis A, Schroeder M, Sagawe V, Ludwig T, Hillebrecht H. Binary Boron-Rich Borides of Magnesium: Single-Crystal Investigations and Properties of $\mathrm{MgB}_{7}$ and the $\mathrm{New}$ Boride $\mathrm{Mg}$ similar to B-5(44). Inorganic Chemistry. 49(23) (2010). 10882-10893. doi:10.1021/ic1012389.

[6]. Sergey Le. Recent advances in crystal growth of pure and chemically substituted MgB $\mathrm{B}_{2}$. Physica. Section C. 456(1-2) (2007). 14-21.doi:10.1016/j.physc.2007.01.018.

[7]. Xu. S, Moritomo. Y, Oikawa. K, Kamiyama. T, Nakamura. A. Lattice structural change at ferromagnetic transition in $\mathrm{Nd}_{2} \mathrm{Mo}_{2} \mathrm{O}_{7}$. Journal of the Physical Society of Japan. 70(8) (2001). 2239-2241. 10.1143/jpsj.70.2239.

[8]. Varghese. N, Vinod. K, Kumar. RGA, Syamaprasad. U and Sundaresan. A. Influence of reactivity of sheath materials with $\mathrm{Mg} / \mathrm{B}$ on superconducting properties of $\mathrm{MgB}_{2}$. Journal of Applied Physics. 4 (2007) 43914(1-4). doi:10.1063/1.2773696.

[9]. Slusky. J.S, Rogado. N, Regan. K.A, Hayward. M.A, Khallfah. P, He. T, Inumaru, K, Loureiro. S.M, Haas. M.K, Zandbergen. H.W, Cava. R.J. Loss of superconductivity with the addition of $\mathrm{Al}$ to $\mathrm{MgB}_{2}$ and a structural transition in $\mathrm{Mg}_{1-x} \mathrm{Al}_{x} \mathrm{~B}_{2}$. Nature. 410(6826) (2001) 343-345. doi:10.1038/35066528.

[10]. Avdeev M, Jorgensen J.D, Ribeiro R.A, Bud'ko S.L. Canfield P.C. Crystal chemistry of carbon-substituted $\mathrm{MgB}_{2}$. Physica C. 387(3) (2015) 301-306.doi:10.1016/S0921-4534(03)00722-6.

[11]. I. Maurin, S. Margadonna, K. Prassides, T. Takenobu, Y. Iwasa, A. N. Fitch. Carbon Miscibility in the Boron Layers of the $\mathrm{MgB}_{2}$ Superconductor. Chemistry of Materials. 14(9) (2002) 3894-3897. doi:10.1021/cm020308k.

[12]. J. Nagamatsu, N. Nakagawa, T. Muranka, Y. Zeniranim and J, Akimitsu. Superconductivity at 39 K in magnesium diboride, Nature. 410(2001) 63-64. doi:10.1002/chin.200121009.

[13]. SD. Bohnenstiehl, MA. Susner, SA. Dregia, MD. Sumption, J.Donovan and EW. Collings. Experimental determination of the peritectic transition temperature of $\mathrm{MgB}_{2}$ in the $\mathrm{Mg}-\mathrm{B}$ phase diagram. Thermochimica Acta. 576(2014) 27-35. doi:10.1016 /j.tca.2013.11.027.

[14]. Balducci. G, Brutti. S, Ciccioli. A, Gigli. G, Manfrinetti. P, Palenzona. A, Butman. MF and Kudin. L. Thermodynamics of the intermediate phases in the Mg-B system. Journal of physics and chemistry of solids. 66(2-4)(2005) 292-297. doi:10.1016 /j.jpcs. 2004.06.063.

[15]. Liu. ZiKui, Schlom. DG and Li. Qi. Computational thermodynamic modeling of the Mg-B system. CALPHAD. 25(2) (2001) 299-303. doi:10.1016/S0364-5916(01)00050-5.

[16]. AA. Nayeb-Hashemi and JB. Clark. Phase Diagram of Binary Magnesium Alloys, ASM International, Metals Park, OH.1988. 
[17]. Liu. ZiKui, Schlom. DG, Li. Qi and Xi. X. Thermodynamics of the Mg-B system: Implications for the deposition of $\mathrm{MgB}_{2}$ thin films. Applied physics letters. 78 (23) (2001) 3678-3680. doi: 10.1063 /1.1376145.

[18]. S. Brutti, A. Ciccioli, G. Balducci and G. Gigli. Vaporization thermodynamics of $\mathrm{MgB}_{2}$ and $\mathrm{MgB}_{4}$. Applied Physics Letters. 80 (16) (2002) 2892-2894. doi:10.1063/1.1471382.

[19]. T. Wenzel, KG. Nickel, J. Glaser, HJ. Meyer, D. Eyidi and O. Eibl, Electron probe microanalysis of Mg-B compounds: stoichiometry and heterogeneity of superconductors. Physica Status Solidi. C. 198 (2) (2003) 374-386. doi:10.1002/pssa.200306625.

[20]. Alapati SV, Johnson JK and Sholl DS, Identification of destabilized metal hydrides for hydrogen storage using first principles calculations. Journal of Physical Chemistry. B. 110 (17) (2006) 8769-8776. doi : 10.1021/jp060482m.

[21]. H. Ozisik, E. Deligoz, K. Colakoglu and E. Ateser, The first principles studies of the $\mathrm{MgB}_{7}$ compound: Hard material. Intermetallics. 39 (2013) 84-88. doi:10.1016/ j.intermet. 2013. 03. 016.

[22]. Arkapol Saengdeejing, Yi Wang and Zi-Kui Liu, Structural and thermodynamic properties of compounds in the Mg-B-C system from first-principles calculations. Intermetallics. 18 (2010) $803 \quad-808$. doi:10.1016/j.intermet.2009.12.015.

[23]. Sungtae Kim, Donald S. Stone, Jaelk Cho, ChangYeol Jeong, ChangSeog Kang and JungChan Bae, Phase stability determination of the Mg-B binary system using the CALPHAD method and ab initio calculations. Journal of Alloys and Compounds.470(2009)85-89. doi:10.1016/j.jallcom.2008.02. 099.

[24]. Ivashchenko. V.I, Scrynskyy. P.L, Dub. S.N, Butenko. O.O, Kozak. A.O, Sinelnichenko. O.K. Structural and mechanical properties of Al-Mg-B films: Experimental study and first-principles calculations. Thin Solid Films. 599 (2016) 72-77. doi:10.1016/j.tsf.2015.12.059.

[25]. Kresse, G.; Furthmüller, J. Effificient iterative schemes for ab initio total-energy calculations using a plane-wave basis set. Phys. Rev. B Condens. Matter 1996, 54, 11169-11186. doi: 10.1103 /PhysRevB. 54.11169 .

[26]. Perdew, J.P; Chevary, J.A.; Vosko, S.H.; Jackson, K.A.; Pederson, M.R.; Singh, D.J. Atoms, molecules, solids, and surfaces: Applications of the generalized gradient approximation for exchange and correlation. Phys. Rev. B Condens. Matter. 46 (1996) 6671-6687.

[27]. JP. Perdew, K. Burke and M. Ernzerhof. Generalized gradient approximation made simple, Phys. Rev. Lett. 77 (1996) 3865. doi: 10.1103/PhysRevLett.77.3865

[28]. Monkhorst, H.J. Special points for Brillouin-zone integrations. Phys. Rev. B Condens. Matter 1976, 16, 1748-1749.

[29]. Chen.XR, Wang. HY, Cheng.Y and Hao.YJ, First-principles calculations for structure and equation of state of $\mathrm{MgB}_{2}$ at high pressure. Physica B: Condensed Matter. 370 (43469) (2005) 281-286. doi:10.1016/j.physb.2005.09.025.

[30]. P. Ravindran, P. Vajeeston, R. Vidya, A. Kjekshus and H. Fjellvåg, Detailed electronic structure studies on superconducting $\mathrm{MgB}_{2}$ and related compounds. Physical Review B. 64(2001) 224509. doi:10.1103/PhysRevB. 64.224509 .

[31]. NASLAIN. R, GUETTE. A and BARRET. M, Magnesium diboride and magnesium tetraboride crystal chemistry of tetraborides. Journal of Solid State Chemistry. 8(1) (1973) 68-85. doi:10.1021 /ja01571a007.

[32]. Birch F, Finite elastic strain of cubic crystals. Physical Review, 71(11)(1947) 809-824. doi:10.1103/PhysRev.71.809. 
[33]. Birch F, Finite strain isotherm and velocities for single-crystal and polycrystalline $\mathrm{NaCl}$ at high pressures and 300 K.Journal of geophysical research-solid earth. 83 (B3) (1978) 1257-1268. doi: 10.1029/JB083iB03p01257.

[34]. F. Mouhat, F.X. Coudert, Necessary and sufficient elastic stability conditions in various crystal systems, Phys. Rev. B 90 (2014) 224104.

[35]. Yang Q, Liu XJ, Bu FQ. First-principles phase stability and elastic properties of Al-La binary system intermetallic compounds. Intermetallics. 60(2015). 92-97. doi:10.1016/j.intermet.2015.02.007.

[36]. Tian. JZ, Zhao. YH, Wang.B, Hou. H and Zhang.YM, The structural, mechanical and thermodynamic properties of Ti-B compounds under the influence of temperature and pressure: First-principles study. Materials Chemistry and Physics. 209 (2018) 200-207. doi:10.1016/j.matchemphys. 2018. 01. 067.

[37]. Hill R, The elastic behavior of crystalline aggregate. Proceedings of The Royal Society A - Mathematical Physical and Engineering Science. 65(1952) 349-354. doi:10.1088/0370-1298/65/5/307.

[38]. JP. Watt and L. Peselnick, Clarification of the Hashin-Shtrikman bounds on the effective elastic moduli of polycrystals with hexagonal, trigonal, and tetragonal symmetries. Journal of Applied Physics.51 (1980) 1525. doi:10.1063/1.327804.

[39]. L. Qi, YC. Jin, YH. Zhao, XM. Yang, H. Zhao and PD. Han, The structural, elastic, electronic properties and Debye temperature of $\mathrm{Ni}_{3} \mathrm{Mo}$ under pressure from first-principles. Journal of alloys and compounds. 621(2015) 383-388. doi:10.1016/j. jallcom. 2014. 10. 015.

[40]. JZ Tian, YH Zhao, H Hou and B Wang. The Effect of Alloying Elements on the Structural Stability, Mechanical Properties, and Debye Temperature of $\mathrm{Al}_{3} \mathrm{Li}$ : A First-Principles Study. Materials. 11.(2018) 1471. doi:10.3390/ma11081471.

[41]. Liu. ZJ, Yan. J, Duan. SQ, Sun. XW, Zhang. CR and Guo. Y, The melting curve of $\mathrm{CaSiO}_{3}$ perovskite under lower mantle pressures. Solid State Communications. 150. (12-14) (2010) 590-593. doi: 10. 1016/j.ssc.2009.12.038.

[42]. Peng Wang, Ning-Chao Zhang, Cheng-Lu Jiang, Fu-Sheng Liu, Zheng-Tang Liu, Qi-Jun Liu. Structural, mechanical, and electronic properties of Zr-Te compounds from first-principles calculations. Chinese Physics B. Philosophical Magazine Letters. 29(7) (2020) 076201.

[43]. ZQ Wen, YH Zhao, H Hou, JZ Tian, PD Han. First-principles study of Ni-Al intermetallic compounds under various temperature and pressure.Superlattices and Microstructures.103 (2017) 9-18. doi:10.1016/j.spmi.2017.01.010.

[44]. SI. Ranganathan and M. Ostoja-Starzewski. Universal Elastic Anisotropy Index. Physical Review Letters.101(5) (2008) 055504. doi:10.1103/PhysRevLett.101.055504.

[45]. A. OterodelaRoza, D. Abbasi-Perez and V. Luana, Gibbs2: A new version of the quasiharmonic model code. II. Models fr solid-state thermodynamics, features and implementation. Computer Physics Communications.182 (10) (2011) 2232-2248. doi:10.1016/ j.cpc. 2011.05.009,

[46]. MA. Blanco, E. Francisco and V. Luana, GIBBS: isothermal isobaric thermodynamics of solids from energy curves using a quasiharmonic Debye model. Computer Physics Communications. 158 (2004) 57-72. doi:10.1016/j.comphy. 2003. 12.001

[47]. Ravindran P, Fast L, Korzhavyi P.A, Johansson B, Wills J, Eriksson O. Density functional theory for calculation of elastic properties of orthorhombic crystals: Application to TiSi ${ }_{2}$. Journal of Applied Physics. 84 (1998) 4891-4904. doi:10.1063/1.368733. 
Figures
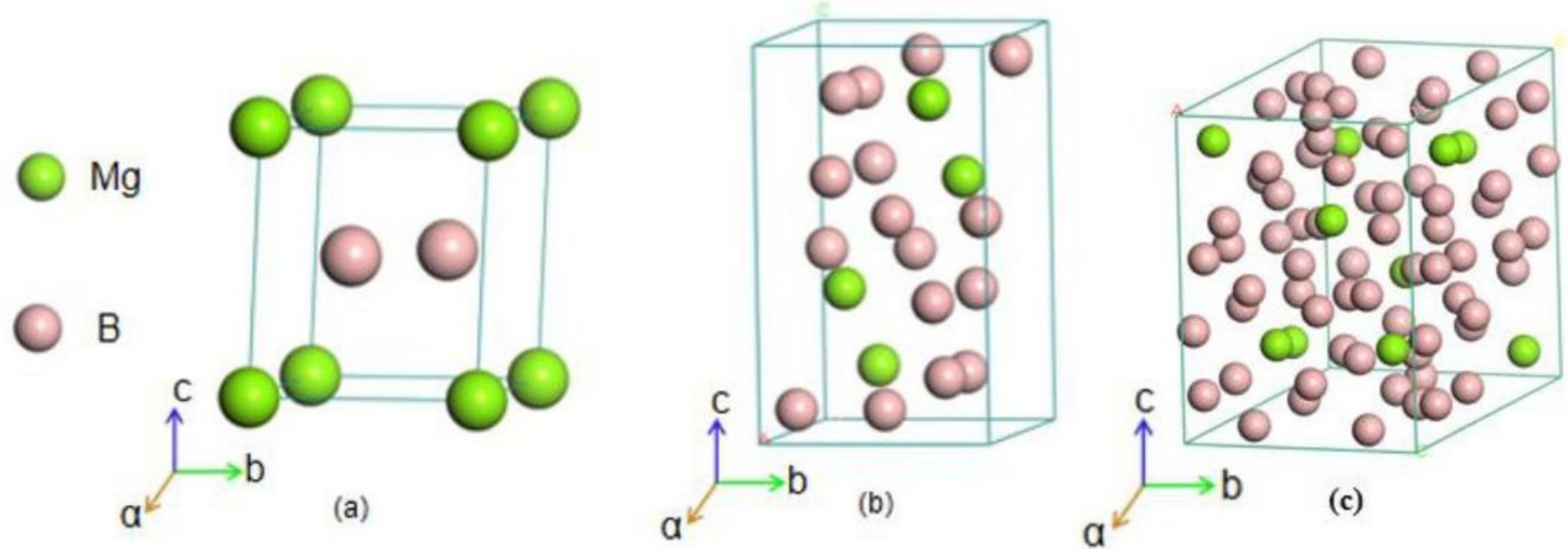

Figure 1

Optimised crystal structures of Mg-B compounds: (a) MgB2; (b) MgB4; (c) MgB7.
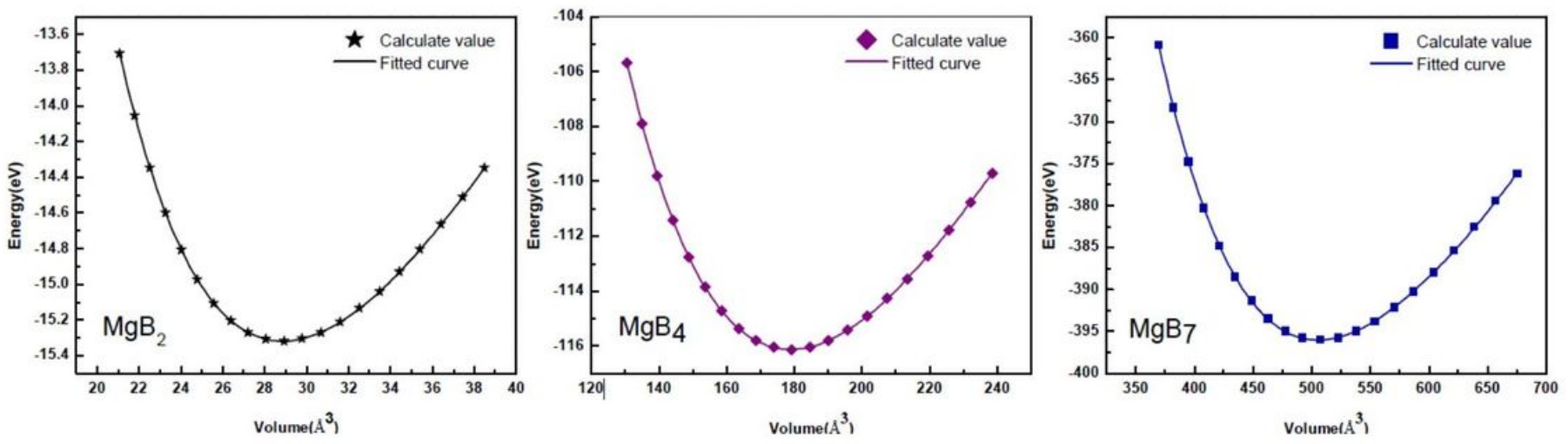

Figure 2

Variation between energy and volume of Mg-B compounds. 


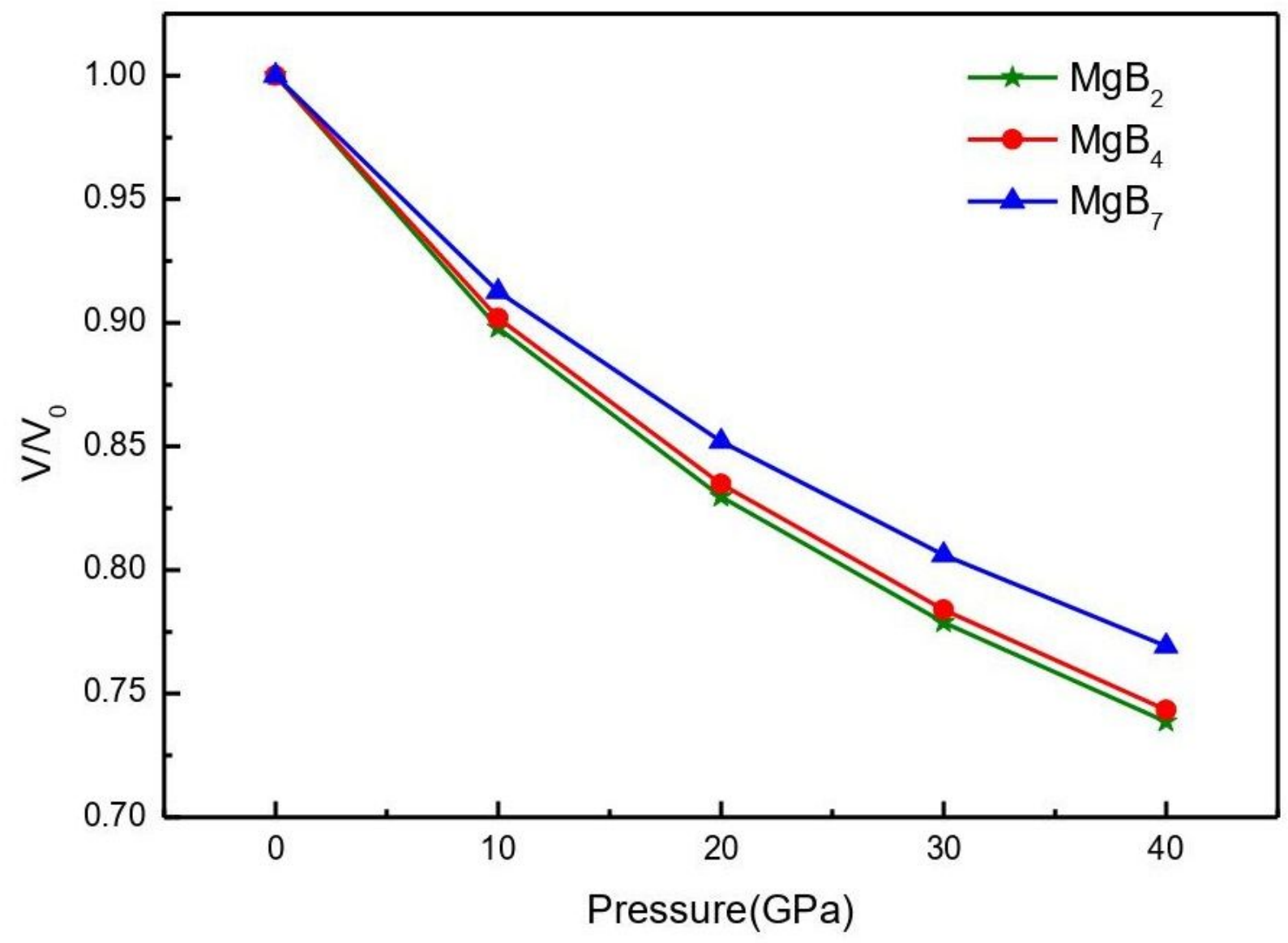

Figure 3

Volume ratio and pressure relation of $\mathrm{Mg}-\mathrm{B}$ compounds with an interval of $10 \mathrm{GPa}$.

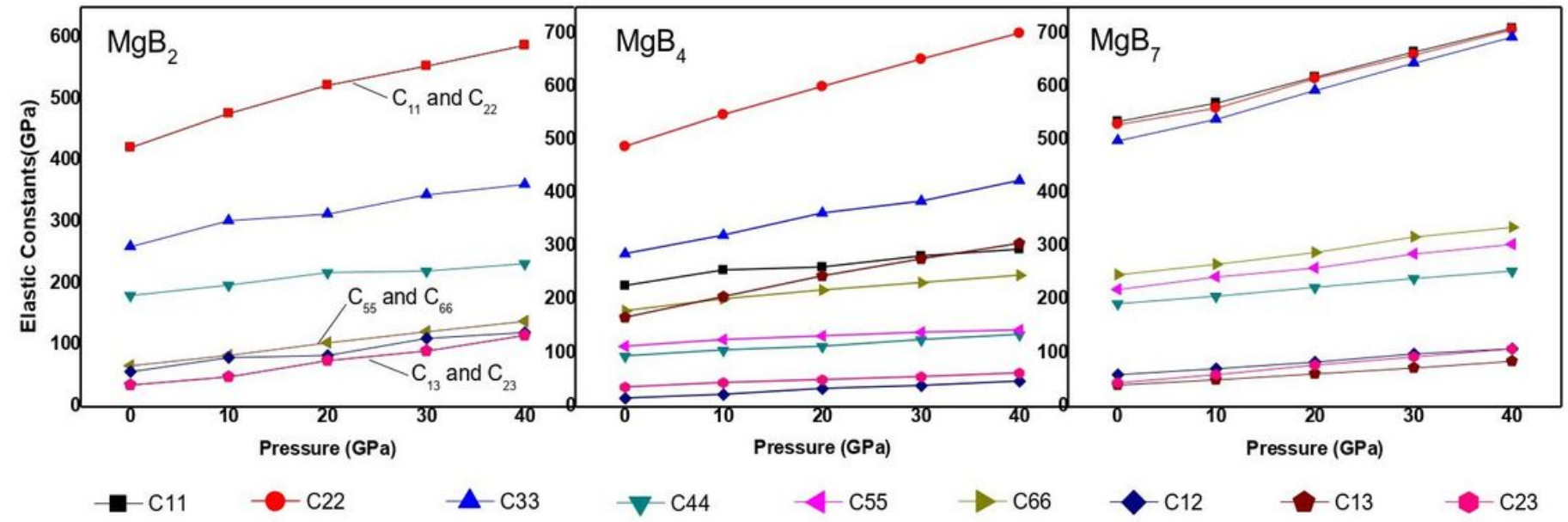

Figure 4

Pressure dependence of the elastic constants of the three Mg-B compounds. 


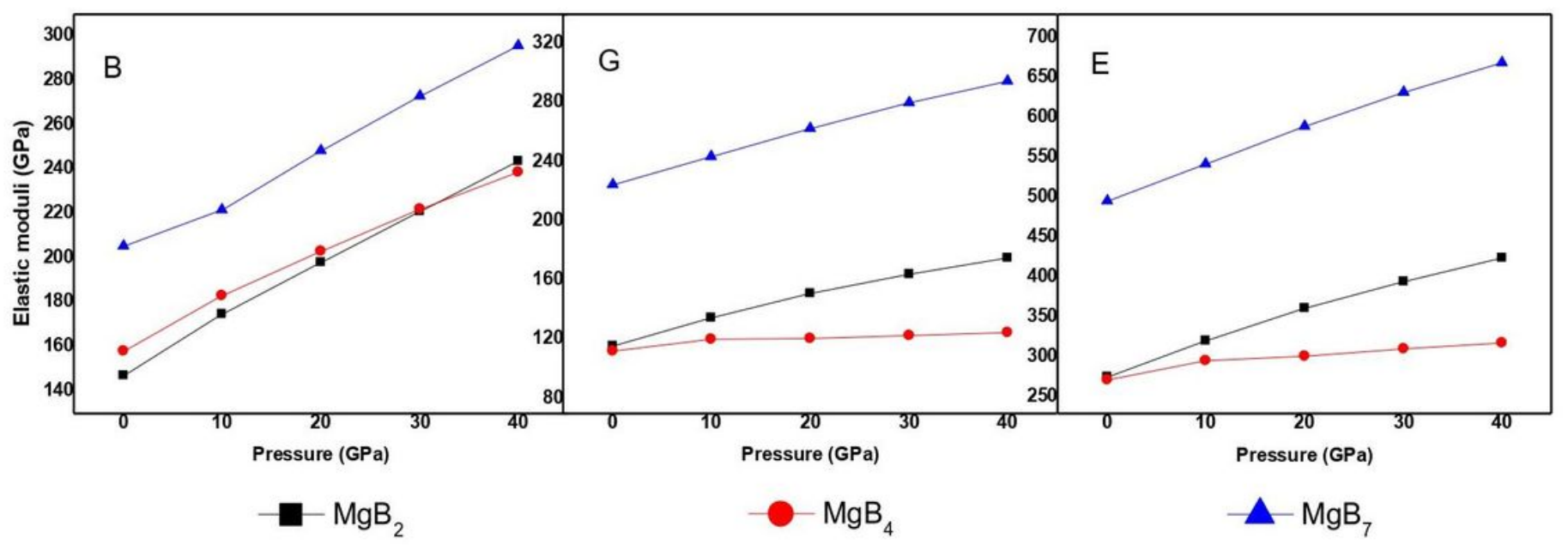

Figure 5

Elastic modulus (B, G, and $E)$ of Mg-B compounds various from different pressure. 


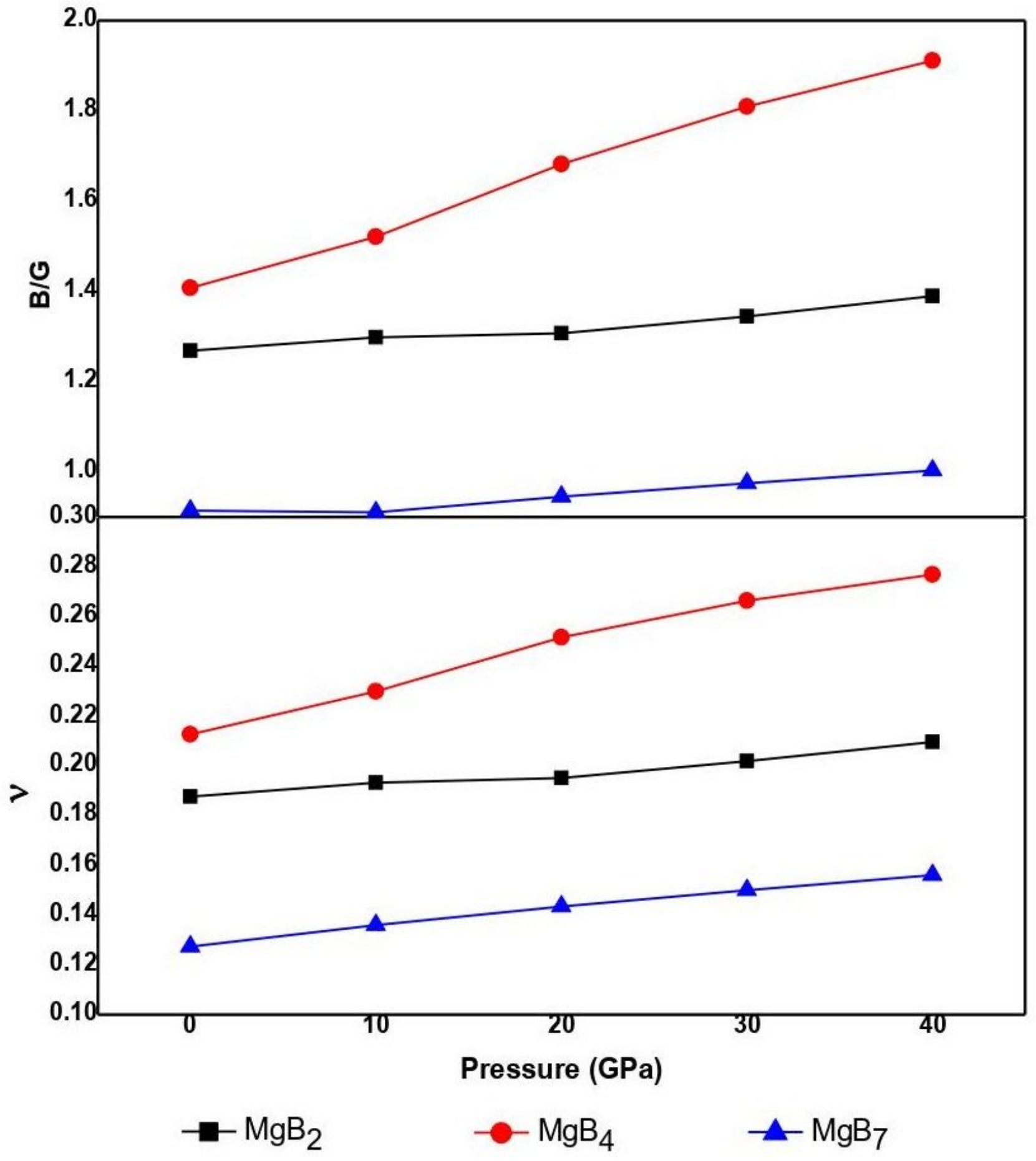

Figure 6

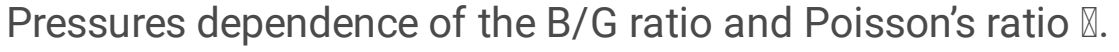




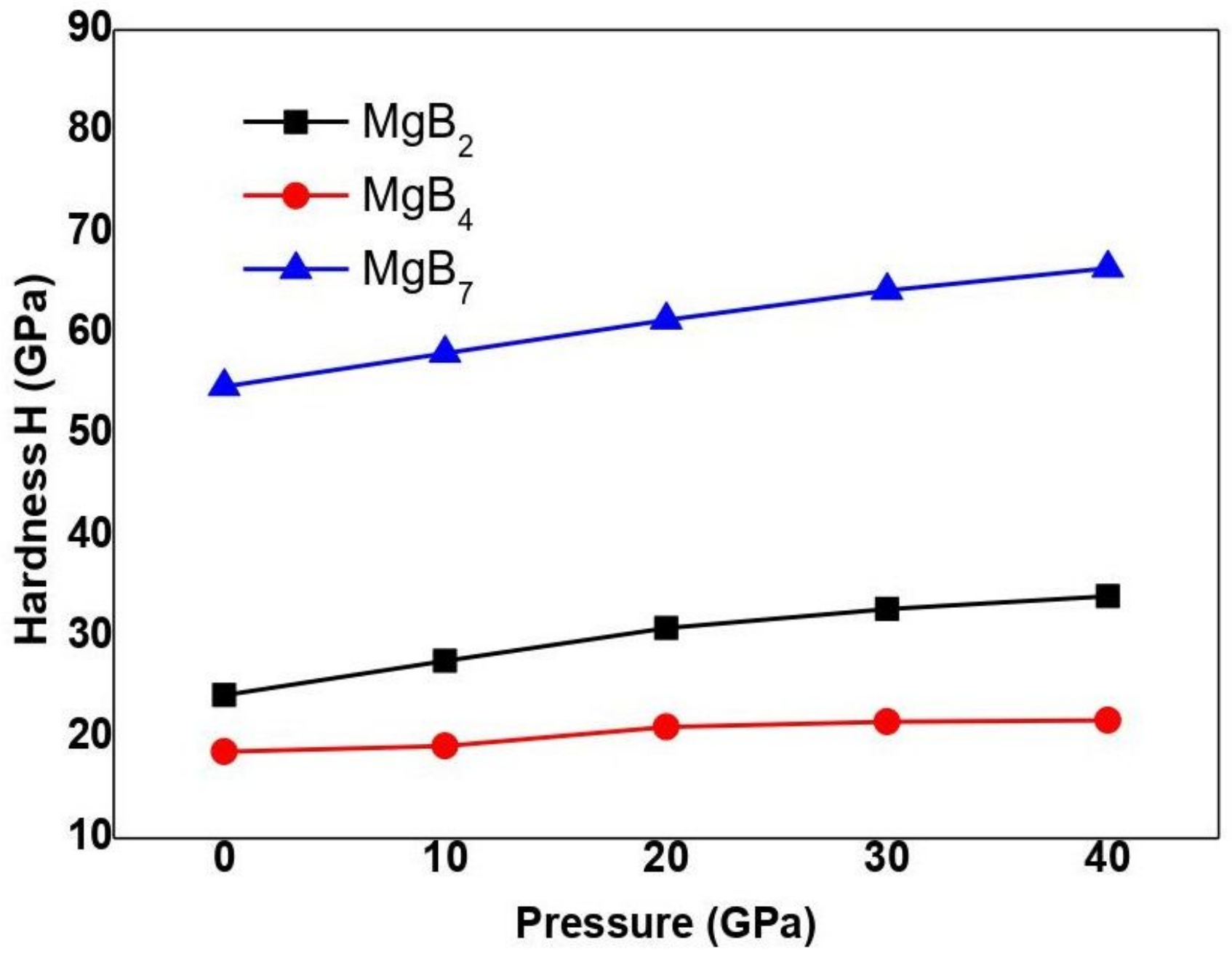

Figure 7

Variation of micro-hardness at various pressures. 

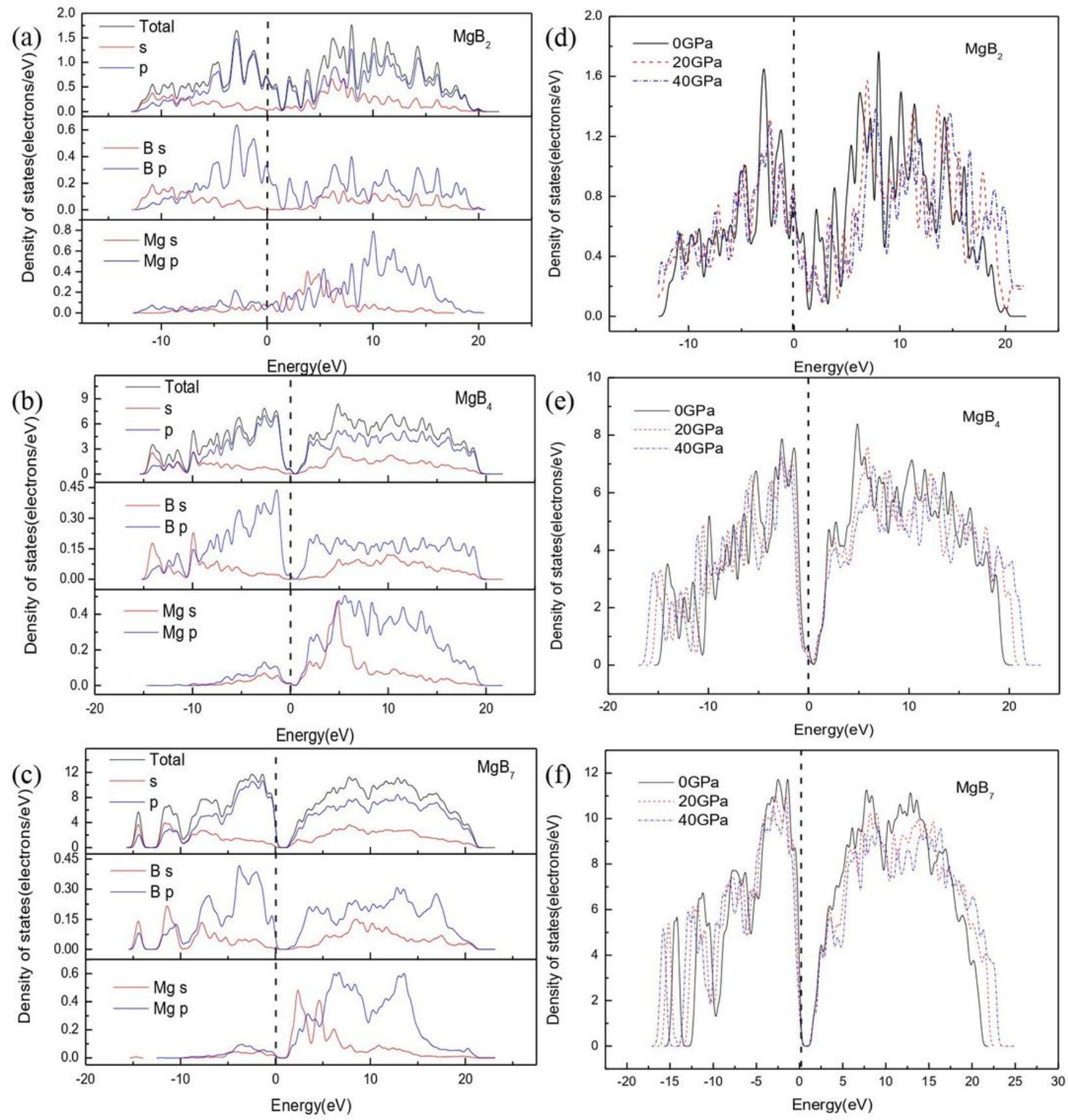

Figure 8

Density of states of Mg-B compounds, (a), (b), and (c) are partial density of states for MgB2, MgB4, and MgB7, respectively; (d), (e), and (f) are total density of states under various pressures for MgB2, MgB4, and $\mathrm{MgB7}$, respectively. 


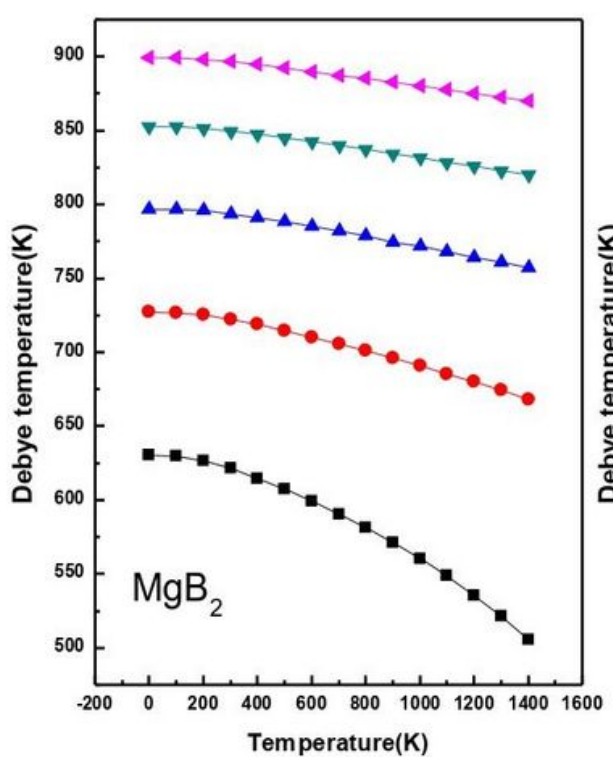

- $-0 \mathrm{GPa}$

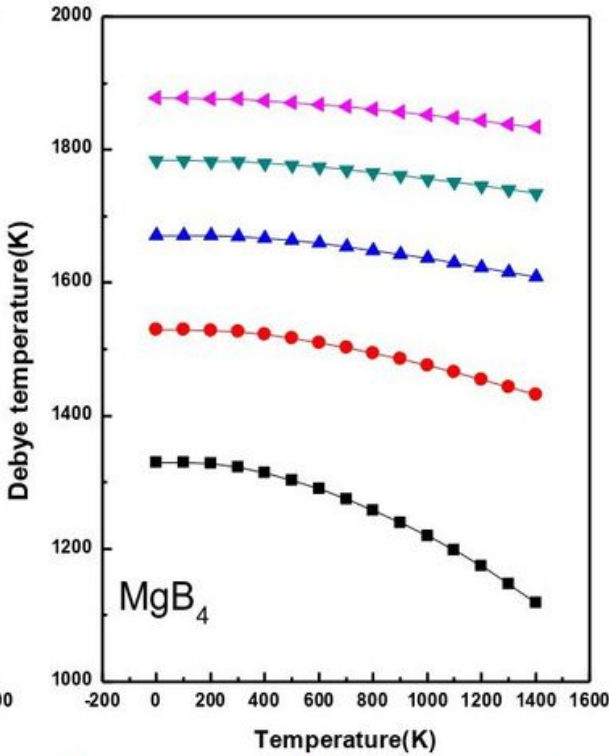

$\triangle 20 \mathrm{GPa}$

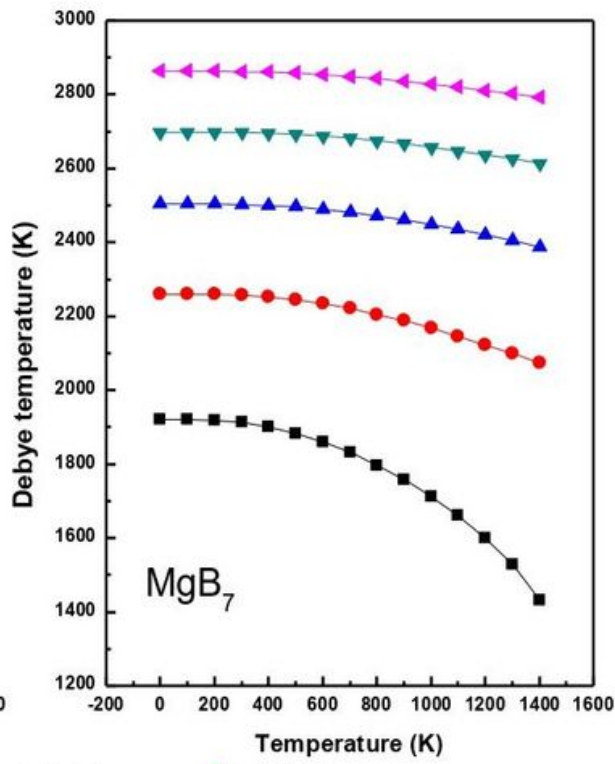

$30 \mathrm{GPa}$

\section{Figure 9}

Debye temperature of $\mathrm{Mg}-\mathrm{B}$ compounds under various pressure and temperature.

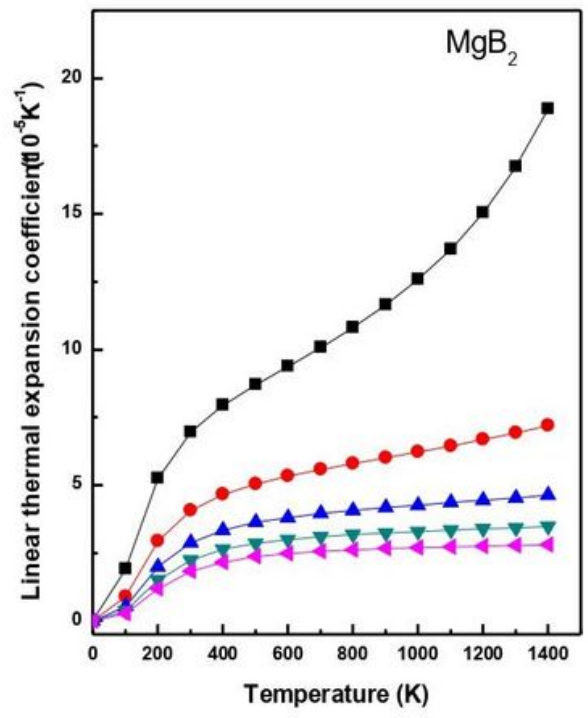

$-0 \mathrm{GPa}$
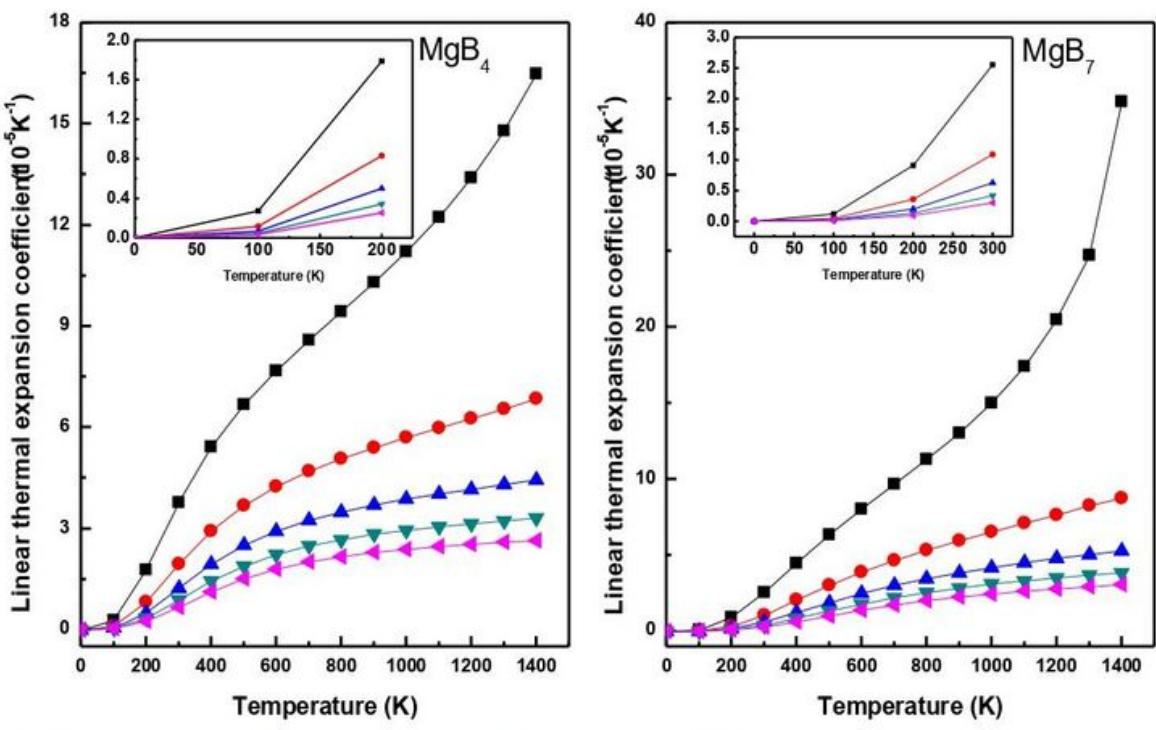

$10 \mathrm{GPa}$

$\triangle$ 20GPa

$\nabla-30 \mathrm{GPa}$

$-40 \mathrm{GPa}$

Figure 10

Linear thermal expansion coefficient of $\mathrm{Mg}-\mathrm{B}$ compounds as function of pressure and temperature. 

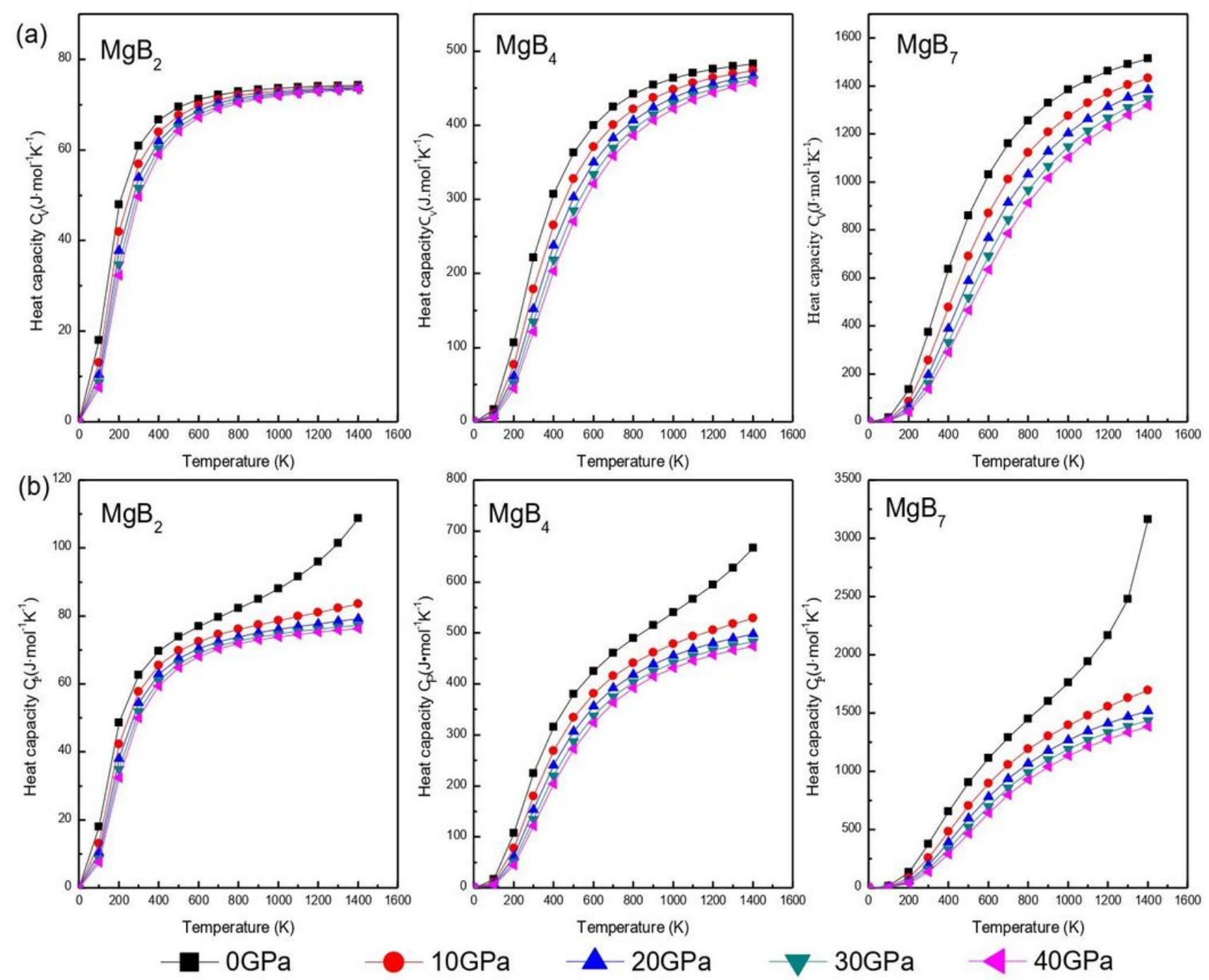

Figure 11

Pressure and temperature dependence of heat capacity $\mathrm{CV}, \mathrm{CP}$ of $\mathrm{Mg}-\mathrm{B}$ compounds. 